\title{
Atypical Brain Asymmetry in Human Situs Inversus: Gut Feeling or Real Evidence?
}

\author{
Guy Vingerhoets* $*$, Robin Gerrits and Helena Verhelst
}

check for updates

Citation: Vingerhoets, G.; Gerrits, R.; Verhelst, H. Atypical Brain Asymmetry in Human Situs Inversus: Gut Feeling or Real Evidence?. Symmetry 2021, 13, 695. https:// doi.org/10.3390/sym13040695

Academic Editor:

Sebastian Ocklenburg

Received: 24 February 2021

Accepted: 14 April 2021

Published: 16 April 2021

Publisher's Note: MDPI stays neutral with regard to jurisdictional claims in published maps and institutional affiliations.

Copyright: (c) 2021 by the authors. Licensee MDPI, Basel, Switzerland. This article is an open access article distributed under the terms and conditions of the Creative Commons Attribution (CC BY) license (https:// creativecommons.org/licenses/by/ $4.0 /)$.
Department of Experimental Psychology, Ghent University, 9000 Ghent, Belgium; robin.gerrits@ugent.be (R.G.); helena.verhelst@ugent.be (H.V.)

* Correspondence: guy.vingerhoets@ugent.be

\begin{abstract}
The alignment of visceral and brain asymmetry observed in some vertebrate species raises the question of whether this association also exists in humans. While the visceral and brain systems may have developed asymmetry for different reasons, basic visceral left-right differentiation mechanisms could have been duplicated to establish brain asymmetry. We describe the main phenotypical anomalies and the general mechanism of left-right differentiation of vertebrate visceral and brain laterality. Next, we systematically review the available human studies that explored the prevalence of atypical behavioral and brain asymmetry in visceral situs anomalies, which almost exclusively involved participants with the mirrored visceral organization (situs inversus). The data show no direct link between human visceral and brain functional laterality as most participants with situs inversus show the typical population bias for handedness and brain functional asymmetry, although an increased prevalence of functional crowding may be present. At the same time, several independent studies present evidence for a possible relation between situs inversus and the gross morphological asymmetry of the brain torque with potential differences between subtypes of situs inversus with ciliary and non-ciliary etiologies.
\end{abstract}

Keywords: situs inversus; heterotaxy; brain asymmetry; visceral asymmetry; vertebrate asymmetry; human laterality; left-right differentiation; brain torque; ciliopathy

\section{A glossary of terms is available at the end of this paper}

\section{Introduction}

Vertebrates' visceral and central nervous systems demonstrate a strikingly asymmetric organization with a strong population bias toward a prototypical left-right configuration [1,2]. As both systems serve fundamentally different biological functions, it seems plausible to assume that the reasons behind their asymmetry may be entirely different and that their left-right differentiation evolved independently. While this may be true, it does not preclude the possibility that basic mechanisms for establishing left-right differentiation of the viscera have been reused to establish central nervous system laterality and that there may be a link between both manifestations of asymmetry. The strong population bias in visceral and brain asymmetry makes it difficult to determine whether they develop independently or related. Research turned to atypical conditions of visceral laterality to investigate possible relationships. Animal studies showed that some species like newts and zebrafish appear to align their brain and visceral asymmetry, mediated by nodalrelated events [3-5]. In the frequent-situs-inversus (fsi) line of zebrafish, visceral reversal is accompanied by neuroanatomical reversals in the diencephalon, particularly epithalamic nuclei, which are believed to be involved in the functional lateralization of the vertebrate central nervous system [6]. In line with this claim, diencephalic reversals of fsi zebrafish correlate with the reversal of some (but not all) lateralized behavioral responses [7]. Do we anticipate a similar association in humans?

We will approach this outstanding question by describing the phenotypes and development of left-right asymmetry of the visceral system and the central nervous system 
and discuss the possible links between their mechanisms of left-right differentiation. Ultimately, a valid test for the hypothesis of an association between human visceral and neural asymmetry is to investigate the prevalence of atypical brain asymmetry in participants with visceral situs anomalies. In a systematic review, we discuss the studies that provide empirical evidence on behavioral, brain functional, and brain structural asymmetries in participants with situs anomalies. However, first, we will briefly explain the relevance of studies on asymmetry for the evolution of development.

Fluctuating asymmetry, directional asymmetry, and antisymmetry constitute three observable types of asymmetry within a population. Fluctuating asymmetry is the amount of deviation from perfect bilateral symmetry, and it manifests as small differences between the left and the right sides due to random errors in individual development. Fluctuating asymmetry is caused by genetic or environmental stress and is taken to measure developmental instability reflecting the level of stress in populations or of individual quality [8]. Directional asymmetry refers to the phenomenon that most individuals in a population are asymmetrical in the same direction, whereas in antisymmetry, dextral and sinistral forms are equally present within a species [9]. The typical asymmetrical position of the internal organs in vertebrates is an example of directional asymmetry, and the equal number of male fiddler crabs with a larger left or right claw is the prototypical example of antisymmetry. The latter two types of asymmetry have been proposed as informative traits to investigate evolution mechanisms as they are easy to define, easy to compare, and have evolved multiple times independently [9]. Differences in the heritability of antisymmetry (absent) and directional symmetry (present) contribute to understanding the evolutionary origin of novel forms, and it has been posited that directional asymmetry appears to have evolved through genetic assimilation (phenotype precedes genotype) almost as frequently as through conventional mutation-mode (genotype precedes phenotype) [9]. Comparing asymmetry patterns across species is relevant to investigate the evolutionary history of gene-expression patterns and anatomical asymmetries. The nodal signaling cascade, which takes a central place in vertebrate asymmetry, provides an important example of cascade capture and trait canalization [9]. In fact, a comparison of the key nodal cascade genes in lower chordates and vertebrates surprisingly suggests that the ancestral target of the nodal cascade might have been brain asymmetry [9].

\section{Left-Right Asymmetry of the Visceral System}

\subsection{Phenotypes of Situs Viscerum}

Like all vertebrates, humans establish left-right asymmetry of the thoracic and abdominal organ position during embryogenesis [1,10]. The position (situs, Latin) of the internal organs (viscera, Latin) in the human body shows a strong population bias toward an asymmetric organization with the heart's apex and aorta, bi-lobed lung, stomach and spleen on the left side of the body midline, and the heart's vena cava, most of the liver and the tri-lobed lung on the right side [11]. This typical configuration is called situs solitus (from Latin, meaning habitual), presents in about $99.99 \%$ of the human population and is taken to reflect optimal packing and transfer of body fluids [11]. Anomalies of this arrangement span a wide range of laterality defects whose classification remains without general consensus, thus hampering pathological, genetic, and epidemiological research [12,13]. As etiological and morphological boundaries between atypical manifestations of visceral situs remain to be settled, there is general agreement on the main two phenotypic subgroups of situs anomalies; the complete or partial reversal of the typical condition termed situs inversus (from Latin, meaning inverted), and the mirroring of either the typical left or right visceral configuration, called heterotaxy (from Greek heteros: other, different and taxis: arrangement) (Figure 1). As a rule, situs inversus and heterotaxy occur in different families, but occasionally they present in the same (often consanguineous) family [14,15]. Epidemiological studies estimate the prevalence of human visceral laterality defects between 1/5000 and 1/11,000 live births [12,16,17]. 


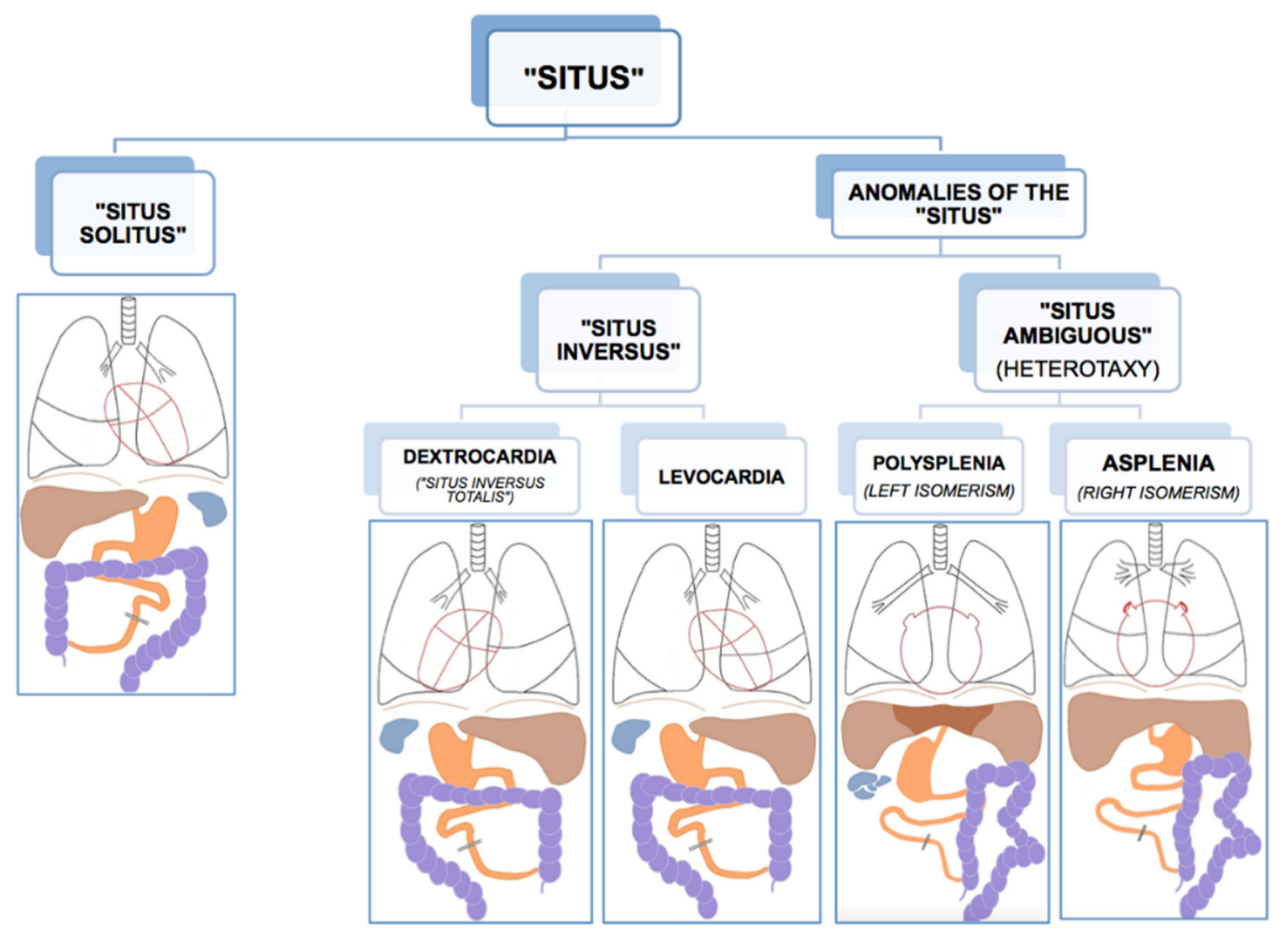

Figure 1. Anatomical dispositions of the viscera in the different types of "situs" (radiological convention). Reprinted with kind permission by Dr. Francisco Barqueros Escuer, https:/ /dx.doi.org/10.26044/ecr2019/C-2735 (accessed on 1 October 2020).

\subsection{Situs Inversus}

Complete reversal of the standard visceral arrangement with the heart now in a right-sided position (dextrocardia) is referred to as situs inversus totalis. Prevalence reports vary widely and have been estimated between $1 / 6000-1 / 33,000$ live births $[12,17,18]$. The condition itself is not associated with adverse medical complications as complete mirroring through the midsagittal plane of organs, blood vessels, nerves, and lymphatics do not interfere with their morphology nor positional relationships [11,19]. People with situs inversus totalis can live perfectly healthy lives, and medical problems may arise only in case of organ transplantation/donation or atypical symptom lateralization (for example, in appendicitis). Because of its limited clinical repercussions, situs inversus totalis is believed to be underdiagnosed. Nevertheless, structural malformations, such as congenital heart disease, may occur more frequently in situs inversus than in situs solitus [20,21]. In rare cases $(1 / 2,000,000)$, situs inversus is not complete, and the heart is in its usual position (levocardia), while the other organs are in reversed position. Isolated levocardia is often associated with severe cardiovascular malformations because of the heart's unusual position compared to the other organs and their connections [20]. In about a quarter of cases, situs inversus occurs as part of a congenital syndrome in which medical complications are more prominent [11]. One of these syndromes, primary ciliary dyskinesia, has elucidated the importance of tiny hair-like organelles (cilia) in the ontogenesis of visceral asymmetry and will be discussed in more detail below.

\subsection{Heterotaxy}

An entirely different type of situs anomaly is heterotaxy, also referred to as situs ambiguus, as the defect presents as a complete loss of left-right laterality in the arrangement of the visceral organs along the superior-inferior axis. In contrast to situs inversus, heterotaxy 
syndrome alters the structure of visceral organs, particularly the heart, including the attachment of the large blood vessels, with the major morbidity and mortality resulting from complex cardiovascular malformations $[13,16,22]$. Prevalence figures for heterotaxy are estimated at $1 / 8000-1 / 12,000$ live births $[12,16,17]$. Although classic heterotaxy accounts for only $3 \%$ of all congenital heart defects, gene mutations causing heterotaxy are also known to result in isolated cardiovascular malformations with no other visceral abnormalities, suggesting that the real prevalence of genetic heterotaxy is probably higher $[19,23]$. Two general types of heterotaxy, called isomerism, are described, although their exact morphology and its resulting abnormalities vary from patient to patient [11,19]. In left isomerism, morphologically left structures present on both sides of the body in the same individual. In this case, atrial cavities are morphologically left, both lungs will be bi-lobar with long main bronchial branches, the spleen is present but consists of multiple small and poorly functioning parts (polysplenia). In right isomerism, the right-sided visceral configuration is copy-mirrored to the left resulting in morphologically right atrial cavities, two tri-lobar lungs with short main bronchi, and an absent spleen (asplenia). In both conditions, the morphologically altered liver lies across the midline of the body, and intestinal malrotation is a typical feature, as well as cardiac malformations, the latter being more severe and sometimes life-threatening in right isomerism.

\subsection{Cause of Visceral Situs Anomalies}

Situs viscerum anomalies are congenital conditions due to heterogeneous genetic mutations that impact left-right patterning in early embryogenesis [19]. Genes involved in left-right axis development have emerged from animal studies and reveal a complex genetic cascade of left-right differentiation prior to the appearance of morphological asymmetry [14]. Most situs anomalies occur due to sporadic mutations, and many different genetic factors or genes cause the condition among different people or families [24]. Environmental and stochastic influences may also play a role as in a substantial number of cases, no clear monogenetic basis for their condition can be found [25]. In some families, situs viscerum anomalies present with an autosomal dominant, autosomal recessive (most commonly), or even X-linked pattern of inheritance [11,19]. Situs anomalies may arise as a variable manifestation of a syndrome encompassing a broader spectrum of defects [11]. Situs inversus, for example, sometimes occurs in cystic renal disease, BardetBiedl syndrome, and retinitis pigmentosa [24]. The best-known example of syndromal situs inversus, however, is when situs inversus arises as a symptom of primary ciliary dyskinesia (PCD), accounting for about 20 to $25 \%$ of its cases $[19,21,26]$. Primary ciliary dyskinesia is a causally heterogeneous group of autosomal recessive disorders characterized by a defect in the motility of small hair-like organelles (cilia) that protrude from the cell surface into extracellular space and perform various transport-related functions in the human body $[27,28]$. Ciliary motility is important for moving fluids and particles over epithelial surfaces, and cilia play crucial roles in various signal transduction pathways. Motile ciliogenesis requires a complex genetic program, and mutations of involved genes have been associated with ciliopathies, including primary ciliary dyskinesia (DNAH5, DNAH11, DNAI1, .. ) [26,28-30]. Ciliopathies give rise to a complex spectrum of disease and developmental mutant phenotypes that can be organ-specific or have broadly pleiotropic effects [31]. The diagnosis of primary ciliary dyskinesia is commonly based on electron microscopy showing abnormalities in structure and function of dynein arms or outright absence of cilia [26]. Affected individuals $(1 / 10,000$ to $1 / 20,000$ live births [30,32]) have chronic upper respiratory tract (sinusitis) and lower respiratory tract (bronchiectasis) infections as well as chronic ear infections (otitis media) due to defective mucociliary clearance $[26,29,33]$. Reduced male fertility caused by decreased sperm motility, variable female infertility, and decreased sense of smell can also be part of the spectrum. About half of the patients with primary ciliary dyskinesia and associated sinusitis and bronchiectasis also have situs inversus (a triad of symptoms known as Kartagener syndrome [34]), while the other half is situs solitus [29]. Given the specificity of the ciliary mutation causing visceral 
inversion versus those causing respiratory problems, most but not all subgroups of the PCD syndrome will affect the genetic cascade induced by ciliary motion at the embryonic node (see below). Hence, the incidence of situs inversus in primary ciliary dyskinesia is estimated slightly less than the often reported $50 \%$, and the Kartagener triad is expected in 1/22,000 live births [32]. Cardiac malformations suggestive of heterotaxy are found in $6-12 \%$ of individuals with primary ciliary dyskinesia [22,35], but it is generally believed that the condition is associated with a (near) randomization of left-right directionality rather than a loss of left-right specification [14]. The occurrence of a monozygotic twin pair with primary ciliary dyskinesia and with discordant visceral situs underlines the arbitrary nature of situs directionality in this condition [36].

\section{Left-Right Visceral Development}

\subsection{Motile Cilia at the Primitive Node}

The vertebrate left-right axis is established after developing its dorsal-ventral and anterior-posterior axes, and it is crucial for the correct positioning and morphogenesis of the internal organs $[1,10]$. The formation of the left-right axis involves several steps that have been investigated in several model organisms, such as the frog, zebrafish, chick, pig, and mouse (for a more detailed account, see [1,10,31,37-39]). While some genetic mechanisms are shared between vertebrates (like the expression of nodal, lefty1, lefty 2 and pitx2), other steps of the process seem to have diverged in evolution [10]. In fact, variation in the nodal cascade among vertebrates was said to resemble an hourglass, a conserved core set of genes listed above, with divergent genetic elements upstream and downstream that largely outnumber the shared core [9]. In most model organisms, symmetry breaking is established at the primitive node, a short-lived embryonic cavity filled with extracellular fluid that forms at the anterior tip of the primitive streak, a line of cells that establishes bilateral symmetry in the embryo, marks its future posterior side, and signals the beginning of gastrulation. Gastrulation is an important period in embryogenesis, which essentially consists of the differentiation of cells into an ectoderm, mesoderm, and endoderm layer. The left-right organizer or primitive node develops about 17 days postovulatory. The formation of the node coincides with the formation of motile cilia whose rotation produces a coordinated and unidirectional flow of the extracellular fluid that will induce symmetry breaking during gastrulation. It is important to point out that earlier asymmetries in the localization of some molecules have been established in some species and it has been claimed that asymmetries might exist perhaps as early as fertilization [37,40]. It is also important to note that not all species have fluid producing nodal cilia (absent in the chick and pig) yet show similarly strong population asymmetries of the viscera, which suggests that alternative cilia-independent symmetry breaking mechanisms at the node exist or that the cilia function as transmitters or amplifiers, but not initiators, of the asymmetrization [40]. In any case, in species with nodal cilia, such as the mouse, fish, and frog, (experimental) disruption of cilia functioning results in situs anomalies [41,42]. Reversal of flow in wildtype embryos results in L-R inversion, and introducing a leftward flow in mutants with ciliopathy restores typical L-R asymmetry [42,43]. While these experimental manipulations of ciliary flow are, of course, not possible in human embryos, the Kartagener syndrome clearly establishes humans as a species in which ciliary malfunction impacts visceral asymmetry. It may seem strange that a lack or impaired nodal flow caused by dysfunctional or absent cilia would result in L-R inversion instead of randomization, but models have been proposed to explain this [44].

\subsection{Propagation of the Signal to the Lateral Plate Mesoderm and Organ Primordia}

Due to their tilt and chiral nature, cilia that arise from nodal cells at the center of the nodal pit produce a clockwise (from tip to base) rotational motion that creates a leftward "nodal flow" towards the left periphery of the node [45] (Figure 2). Fluid flow is sensed by mechanosensory and/or chemosensory cilia in peripherally-located crown cells at the lateral ends of the pit [42]. These events cause intracellular $\mathrm{Ca}^{2+}$ levels to 
increase on the left side of the node, which results in asymmetries in gene expression and the establishment of a L-R axis [31]. The resulting asymmetric gene expression is then propagated to the lateral plate mesoderm-sheets of embryonic tissue at the peripheral left and right side of the embryo that will form the body wall and circulatory system-where a cascade of asymmetric left-sided gene expression is established (nodal, lefty2, pitx2). Several mechanisms have been proposed to explain the propagation of signaling from the node to the lateral plate mesoderm either directly by diffusion of nodal or by a cascade of signaling events via sonic hedgehog ( $\mathrm{sh}$ ) or bone morphogenetic protein (bms) that asymmetrically affect nodal expression [1]. In any case, the expression of nodal and the lefty genes (nodal antagonists) is transient and exclusively on the left side [1]. Finally, this asymmetric signaling is propagated from the lateral plate mesoderm to organ primordia for proper morphogenesis of the viscera to occur (pitx2). It is proposed that nodal acts as a determinant for leftness because cells that receive nodal signals will adopt left-side morphology, and those that lack nodal signals will adopt right-side morphology. In mutations in which nodal is bilaterally expressed in the lateral plate mesoderm, embryos will develop left isomerism, and in those that lack nodal signal on either side, embryos will develop right isomerism [1]. While heterotaxy may result from deficits in any of the above steps, they more often occur at one of the later stages. Situs inversus, on the other hand, is believed to originate from a more initial deficit in nodal flow caused by defectively operating cilia when the total direction of left-right asymmetry is determined. Animal models identified over 100 genes involved in left-right patterning, and more are to come [24]. Their mutations, in combination with reduced penetrance and variable expressivity, predict vast differences in phenotypical presentation of situs anomalies.

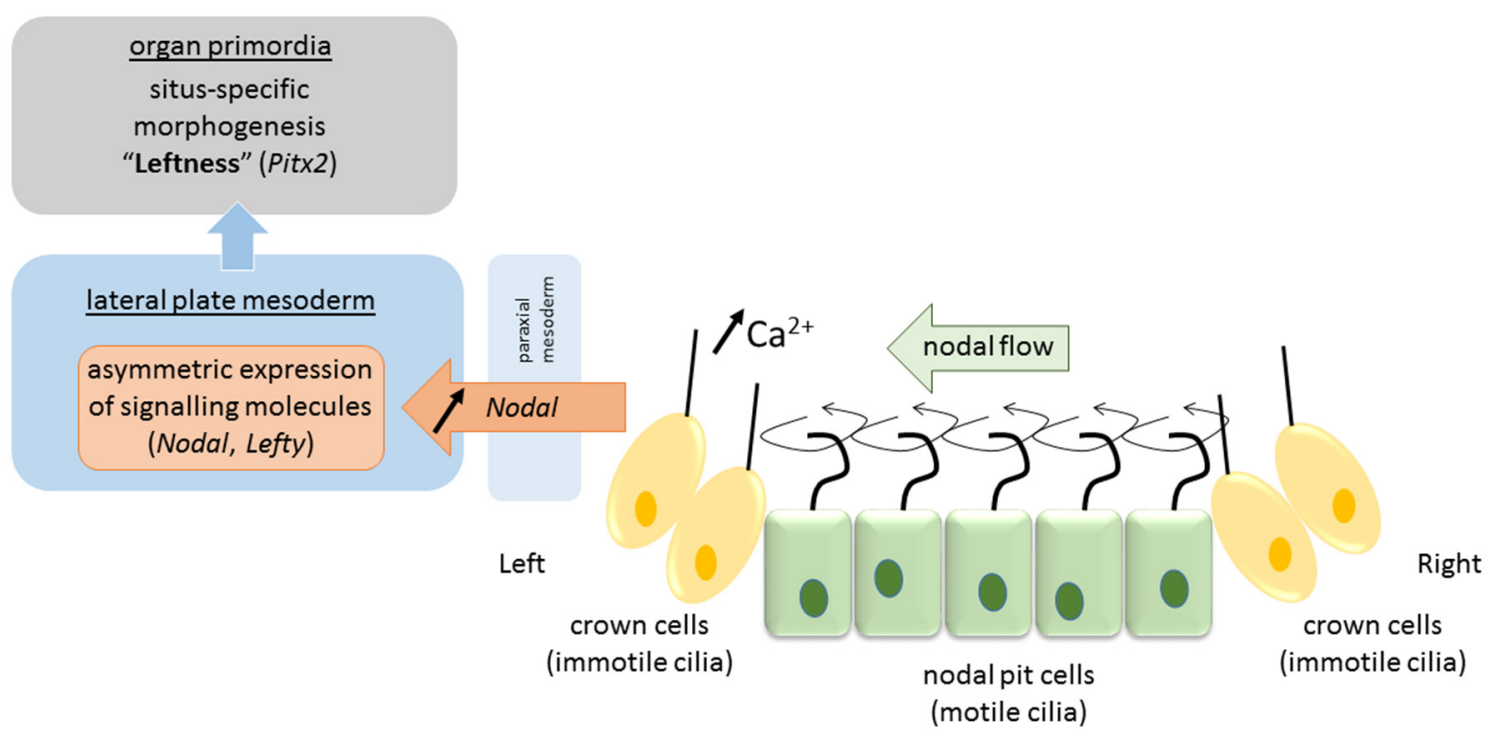

Figure 2. Pathway of visceral left-right determination in the vertebrate.

\section{Left-Right Asymmetry of the Neurocognitive System}

Like the visceral organs, our mental organs, by which we mean the biological substrates of cognitive functions, are asymmetrically represented in the brain. The advantages of hemispheric functional lateralization are explained in terms of improved parallel processing and the avoidance of useless duplications that saves neural space and evades competition between redundant control centers [46,47]. In addition to a bias favoring an asymmetric brain functional organization, there is also a bias toward a prototypical asymmetric configuration at the level of the population. Most humans have their left hemisphere in charge of language, manual dexterity (giving rise to handedness), and praxis (learned gestures), and the right hemisphere in control of spatial attention, face recognition, and prosody of speech [2]. The asymmetric arrangement gives rise to functional segregation 
between the left and right hemispheres. The existence of a population bias for exactly this configuration suggests that it may possess a biological advantage, but it remains to be explained why and how this would be the case. One possible way to look into this is by investigating alternative configurations of brain organization and explore their relationship with behavior.

\subsection{Phenotypes of Brain Functional Organization}

Recently, we have argued for the existence of three major categories in the phenotypes of functional brain segregation: typical, reversed typical, and atypical functional segregation [2]. Evidence for this distinction comes from studies investigating the asymmetry of more than one function in the same individuals. In random sample studies, this is achieved by investigating a random sample of the population [2]. The results of the available random sample studies are summarized in Table 1. Most studies probed two asymmetric functions. All used a language task as a typically left hemispheric function, and most used a spatial task to investigate right hemisphere dominance. Results reveal that most people show typical lateralization of the investigated functions and that a (substantial) minority of about $30 \%$ does not conform to this typical pattern (though many studies oversampled left-handers, which may have boosted this prevalence estimate). In about $20 \%$ of the participants, usually segregated functions were lateralized in the same hemisphere, a condition called crowding as the hemisphere is more crowded with functional representations. In about $10 \%$ of the participants, all investigated functions were lateralized in the atypical hemisphere resulting in a mirrored image of the prototypical functional segregation [2]. Evidence that this mirrored pattern of functional segregation extends beyond two atypically lateralized functions comes from selective sample research. In this type of investigation, participants are recruited based on the atypical lateralization of one function (usually language) to probe the lateralization of other functions. All these studies have been performed in left-handers as they are known to have a higher prevalence of atypical language dominance and revealed a concomitant reversal of the other investigated function [48-50]. In a recent study, five different lateralized functions were tested, and about $80 \%$ of the participants that had atypical language lateralization demonstrated complete or near complete reversal of all other functions as well [51]. In the remaining 20\%, typical (or reversed typical) functional segregation was compromised more substantially, with two functions showing atypical lateralization, while the other three functions had conventional lateralization [51].

Table 1. Random sample studies that investigated more than one lateralized function in the same individuals.

\begin{tabular}{|c|c|c|c|c|c|c|c|}
\hline Author and Year & LH Function & RH Function & $\mathbf{N}$ (\#Sinistrals) * & Typical & Reversed & Crowded & Method ** \\
\hline $\begin{array}{l}\text { Bryden et al., } \\
1983 \text { [52] }\end{array}$ & Language & Spatial dysfunction & $270(140)$ & $\begin{array}{l}72 \%(\mathrm{RH}) \\
47 \%(\mathrm{LH})\end{array}$ & $\begin{array}{l}12 \%(\mathrm{RH}) \\
12 \%(\mathrm{LH})\end{array}$ & $\begin{array}{l}16 \%(\mathrm{RH}) \\
44 \%(\mathrm{LH})\end{array}$ & Lesions \\
\hline $\begin{array}{c}\text { McNeely and Parlow, } \\
2001 \text { [53] }\end{array}$ & Language & Prosody & $73(7)$ & $78 \%$ & $22 \%$ & $0 \%$ & $\begin{array}{l}\text { Dichotic } \\
\text { listening }\end{array}$ \\
\hline $\begin{array}{l}\text { Floël et al. } \\
2005 \text { [54] }\end{array}$ & Language & Spatial attention & $75(38)$ & $\begin{array}{l}95 \%(\mathrm{RH}) \\
60 \%(\mathrm{LH})\end{array}$ & $\begin{array}{c}2.5 \%(\mathrm{RH}) \\
8 \%(\mathrm{LH})\end{array}$ & $\begin{array}{l}2.5 \%(\mathrm{RH}) \\
32 \%(\mathrm{LH})\end{array}$ & fTCD \\
\hline $\begin{array}{l}\text { Whitehouse and } \\
\text { Bischop, } 2009 \text { [55] }\end{array}$ & Language & Spatial memory & $75(30)$ & $75 \%$ & $0 \%$ & $25 \%$ & fTCD \\
\hline $\begin{array}{l}\text { Badzakova-Trajkov } \\
\text { et al. } 2010 \text { [56] }\end{array}$ & Language & $\begin{array}{l}\text { Spatial attention } \\
\text { Face processing }\end{array}$ & $155(48)$ & Majority & $2 \%$ & Rest & fMRI \\
\hline $\begin{array}{l}\text { Rosch et al., } \\
2012 \text { [57] }\end{array}$ & Language & Spatial attention & $20(0)$ & $65 \%$ & $15 \%$ & $20 \%$ & fTCD \\
\hline $\begin{array}{l}\text { Groen et al., } \\
2012[58]\end{array}$ & Language & Spatial memory & $60(13)$ & $58 \%$ & $5 \%$ & $32 \%$ & fTCD \\
\hline $\begin{array}{l}\text { Zago et al., } \\
2016 \text { [59] }\end{array}$ & Language & Spatial attention & $293(151)$ & $80 \%$ & $3.5 \%$ & $15 \%$ & fMRI \\
\hline Estimated proportion & & & & $\pm 70 \%$ & $\pm 10 \%$ & $\pm 20 \%$ & \\
\hline
\end{tabular}

* Many "random-sample" studies included a proportionally higher number of left-handers to explore the effect of handedness; ** fTCD: functional transcranial Doppler ultrasonography; fMRI: functional magnetic resonance imaging. 


\subsection{Reversed Typical Functional Segregation}

Together, these data confirm typical functional segregation in the majority of people, but they also show that alternative arrangements are not uncommon [2]. One alternative phenotype is a mirror reversal of typical functional segregation, which so far has been documented exclusively in left-handers [51]. Brain-wise, the reversed typical segregation phenotype is somewhat comparable with the visceral anomaly of situs inversus totalis, although its human population prevalence seems at least 100 times higher. Most random sample studies found no correlation between the laterality of different functions, suggesting that functions lateralize independently from other functions' laterality. Independent lateralization seems difficult to reconcile with a complete or near-complete reversal of five asymmetric functions in the same individual, let alone in $80 \%$ of a selective group. The odds that five independently lateralizing functions would each assume dominance in the atypical hemisphere in the same individual is extremely small. One way of reconciling independent lateralization and the observation of reversed typical functional segregation is achieved by assuming the existence of a generic blueprint of functional brain organization. Functions can develop their degree of lateralization more or less independently from other functions, but the origin of this process is seeded in a directional building plan that, on rare occasions, seems to have been flipped [2]. This assumption can explain the phenotype of the mirrored mind (mens inversus totalis, from mens, mentis (Latin) meaning mind) and at the same time allows for the independence of functional laterality indices. The assumption also predicts that the frequency by which functions occasionally deviate from the standard pattern (crowding) is not very different between the typical and reversed typical conditions as both mechanisms (independency of lateralization degree and reversal of the directional blueprint) are likely to be unrelated.

\subsection{Atypical Functional Segregation}

A second alternative phenotype groups conditions that show a more chaotic pattern of lateralization, as seen in individuals that have some functions showing typical and others showing atypical asymmetry. In these cases, the habitual functional segregation seems to be lost [2]. The visceral homolog of this phenotype category that we termed atypical functional segregation seems more akin to heterotaxy, where a loss of left-right asymmetry in the arrangement of the visceral organs is assumed, and that presents vast individual differences in organ displacement. While this comparison may seem farfetched at first, it has been raised before in the context of dissociated functional laterality [60], and there are more similarities between both conditions than meet the eye: variability of presentation, functional impact, and isomerism. As described above, the individual presentation of heterotaxy is very diverse, and the same gene mutation may cause severe heterotaxy affecting different organs in one individual and isolated cardiovascular malformation with no other visceral abnormalities in another. Similarly, atypical functional segregation can result from one or multiple functions deviating from the prototypical constellation [51]. Heterotaxy impacts the relationship between organs and is associated with more frequent and more severe medical problems than is situs inversus. Likewise, we reported evidence that healthy participants who show increased deviation from standard brain functional segregation perform significantly worse on a neuropsychological test battery compared to participants with typical or reversed typical segregation, suggesting that atypical functional segregation may be cognitively disadvantageous [51,61]. Finally, heterotaxy, at least theoretically, presents as two possible categories or isomerisms that copy-mirrors the left or right visceral morphology to both sides of the body. The brain functional homolog of this manifestation might be bilateral functional representation. Although bilateral functional representation has not been investigated at a multifunction level, it has received some attention at the single-function level. Research has shown that a small group of right and left-handers do not show clear-cut lateralization for language [62]. This group is said to have mixed or bilateral representation for language. Analyzing the left and right hemispheric activation patterns of these participants with a machine learning approach 
distinguished participants with a bilaterally dominant language representation from those with a bilaterally non-dominant pattern [63]. These findings are in line with observations from pre-surgical Wada-testing where some patients show speech arrest following sedation of either hemisphere, and other patients do not show speech arrest following sedation of either hemisphere [64-66].

In summary, alternative organizations of hemispheric functional segregation can be distinguished in two broad phenotypical categories that show at least some common properties with the main phenotypical subgroups of visceral anomalies. It remains to be determined whether these similarities are merely the product of the finite set of options imposed by our categorization or whether they reflect more fundamental principles that share a biological mechanism.

\section{Left-Right Brain Development}

\subsection{Neurulation}

The origin of brain symmetry breaking remains to be determined, but here too, an uneven distribution of molecules is believed to initiate left-right patterning [67]. During gastrulation and opposite to the primitive streak, the ectodermic tissue thickens and flattens to become the neural plate (about 19 days postovulatory). During that stage, the notochord appears below where the primitive streak and node used to be in the mesodermic tissue, and which will induce the start of neurulation. Neurulation is the process where the ectodermal neural plate folds into a neural tube (about 25 days postovulatory). The neural tube will later develop into the central nervous system (CNS). Primary cilia are involved in neurulation by neural tube patterning and closure through regulation of Sonic hedgehog signaling, and also in neural stem cell pool regulation, neural differentiation, and migration [68]. During neural tube development, its most ventral part, adjacent to the notochord, becomes the floor plate, and its dorsal part becomes the roof plate. The floor and roof plates, respectively, project ventralizing (nodal, lefty, shh) and dorsalizing (bone morphogenetic protein (bms) that suppress default neural differentiation and instead promotes epithelial growth) inductive signals to the developing neural tube, of which its most rostral part will develop into the forebrain (Figure 3). Asymmetric secretion of morphogens from the floor and roof plates to the left and right sides of the neural tube is believed to break the symmetry of neural patterning and induce asymmetric expression of downstream genes $[67,69]$. In addition to the floor and roof plates, the most rostral part of the neural tube has a third patterning center, the anterior neural ridge. The anterior neural ridge is a major organizing center that emits rostralizing signals essential for developing the secondary prosencephalon (that will form telencephalon, thalamus, hypothalamus, and epithalamus) $[67,69]$. It has been suggested that the asymmetric expression of morphogens secreted from this region could reflect asymmetrical topographic mapping of functional regions in the cortex $[70,71]$.

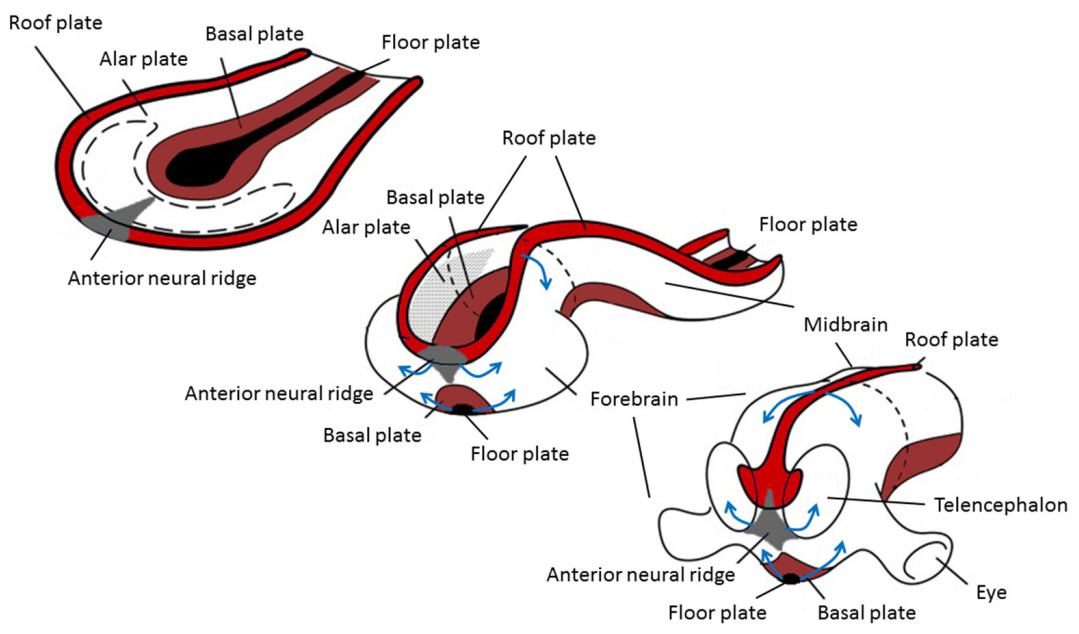

Figure 3. Changes during neurulation of the anterior neural section. Reprinted with permission from [72] and modified. 


\subsection{Asymmetric Development of the Central Nervous System}

Empirical data on the asymmetry of gene expression in the left and right forebrains and midbrains of human embryos are available from 5 post-conception weeks onward [73]. By pooling data from voluntary medical abortions of healthy pregnancies and the Human Developmental Biology Resource (UK), the authors observed transcriptomic laterality in the anterior CNS regions of embryos between 5 and 14 weeks after conception. By joining the anterior CNS data with previous results of the midbrain and spinal cord regions of 4 to 8 week-old human embryos, the authors further reported evidence of age-dependent laterality of transcriptomic profiles for most structures indicating subtle differences in maturation rates between left and right CNS structures [73,74]. While both sides go through the same general developmental changes, one side appears to lead the other side at certain stages, and the laterality of the faster side is different from structure to structure. At 5 to 5.5 weeks post-conception, the spinal cord shows faster maturation on the left side than on the right, while the opposite pattern is observed for the midbrain and hindbrain [74]. By 7.5 weeks post-conception, the left choroid plexus, basal ganglia, diencephalon, and temporal cortex show faster maturation rates, but the rest of the cerebral cortex matures faster on the right side [73]. The observation of an early and differentiated pattern in the asymmetry of CNS structures with different functional destinations has led the authors to propose that brain asymmetry may be initiated/amplified at multiple locations [73]. For example, if faster maturation of the left spinal cord reflects observations of predominant right arm movements at 8 weeks post-conception (that is, prior to the innervation of the descending corticospinal tracts into the spinal cord), this could set the stage for the later cortical laterality of handedness, but would not necessarily influence the laterality of other functions or regions [73]. This suggestion is consistent with the weak correlations between the adult laterality of different brain functions like handedness and language [62] and with the results of gene ontology analysis that support the idea that handedness and language lateralization are ontogenetically independent phenotypes [75]. While subtle brain asymmetries in gene expression are already measurable at 5 weeks post-conception (i.e., approximately 7 weeks of gestational age), structural human fetal brain asymmetries become visible with current methods by the 11th week of gestational age for the choroid plexus [76], by the 16th week for the fetal cortex volume [77], by the 18th week for temporal lobe morphology [78], by the 20th week for sulcal folding [79,80], and by the 26th week for perisylvian hallmarks that have been associated with language [81]. The gap between genetic and morphological or functional brain asymmetries remains to be detailed [60].

\section{Are Asymmetries of Visceral and Brain Development Related?}

Visceral and neural patterning commence in close temporal proximity during the third and fourth week of human gestation, but it remains unclear whether the mechanisms that regulate visceral asymmetry also impact brain asymmetry. Asymmetric gene expression and the role of cilia seem potentially important factors for a link between visceral and brain manifestations of asymmetry.

Although nodal and shh pathways are also expressed during neurulation (cfr. floor plate induction), none of the reported 27 genes found to be differentially expressed in the left and right hemispheres of 12-14-week-old human fetal brains have known essential roles in visceral organ asymmetry [70]. Similar findings of lateralized gene expression with the more modern technique of transcriptomic profiling in post mortem temporal cortex from embryo to old age were reported, but here too, none of the reported genes have been associated with visceral anomalies [82]. On the other hand, relative hand skill in a cohort of individuals with a reading disability was associated with a variant in the gene $p c s k 6$, an enzyme that cleaves nodal into an active form [83]. Pcsk6 knockout mice display heterotaxy, and human variants of this gene are associated with heterotaxy and situs inversus as well, suggesting that handedness is at least in part controlled by genes that contribute to the determination of visceral asymmetry [83]. Human genes, like GPC3, associated (though not 
significant at a genome-wide threshold) with relative hand skill in the general population, cause situs anomalies when their orthologs are knocked out in mice [83,84].

Clinical evidence demonstrates the importance of cilia in human neurulation. Major ciliopathy-associated hereditary cerebral anomalies include neural tube defects, corpus callosum malformations, cerebellar hypoplasia, and hydrocephaly. Less severe neurological features, including cognitive deficits, autism spectrum disorders, and seizures, are also frequently observed in individuals with ciliopathies and hint at the possibility of more subtle cortical deficiencies [68]. Concerning laterality, genes most strongly associated with relative hand skill in a dyslexia cohort are involved in ciliogenesis, and their disruption in mice causes situs inversus [83,84]. In addition, cilia-related gene sets are more highly expressed in the right choroid plexus in the 7.5-13 post-conception age range [73]. The choroid plexus is also the first brain structure showing morphological asymmetry and is associated with the circulation of cerebrospinal fluid in the ventricles. Despite these observations, there is no clear evidence that cilia play a role in the initiation or propagation of central nervous system asymmetry [73].

\section{Atypical Brain Asymmetry in Human Visceral Situs Anomalies}

As the molecular regulation of brain asymmetry and its relationship with visceral lateralization remains to be elucidated, an alternative strategy of investigation is to look for evidence of atypical functional or structural brain asymmetry in people with situs anomalies. If the prevalence of behavioral, brain functional, or brain structural asymmetry differs between participants with typical and atypical visceral situs, then research would be better informed to explore more specific pathways of a possible link between human visceral and brain asymmetry. This approach is confronted with two major limitations: sample size and heterogeneous causality. As situs anomalies are inherently rare, it is extremely difficult to recruit many participants with atypical organ situs, especially if more intensive research protocols like neuroimaging are applied. In the absence of striking relations, small samples limit the statistical power to detect more subtle differences between typical and atypical groups in particular when only a subsample of participants shows a relation and others do not. This brings us to the second limitation of this approach, the heterogeneity of factors (genetic and other) that contribute to brain and visceral asymmetries. Different manifestations of situs anomalies have been associated with different genetic mutations, suggesting that genetic screening or at least a thorough description of the situs condition and family history should be used for categorization. Many gene mutations and combinations thereof have been associated with anomalies in visceral left-right patterning, and they are known to affect different steps and mechanisms of this complex process. It is plausible that some gene mutations bear no relation with brain asymmetrization, while others do. For example, in primary ciliary dyskinesia, the resulting randomization of organ situs is due to genetic mutations causing ciliary dysfunction. While cilia have a role in neurulation, it is unclear whether this includes lateralization of morphogens that induce brain asymmetry. Hence, a ciliopathy like primary cilia dyskinesia may not affect developing brain asymmetry at all. It is also possible that in people with situs inversus that have no primary ciliary dyskinesia, the origin of their situs anomaly is due to a temporary (or local) malfunction of nodal cilia or is caused by a different mechanism altogether. Even within the subgroup of situs inversus, etiological heterogeneity is substantial and extends beyond the role of genes. This was illustrated in a recent genome sequencing study of 15 cases with situs inversus totalis (SIT) [25]. The subgroup of six participants with primary ciliary dyskinesia (PCD) all presented with likely recessive PCD-associated mutations. Similar mutations were also detected in two of the non-PCD SIT participants, and in two other non-PCD SIT participants, recessive mutations in genes linked to situs inversus outside the context of PCD were found. In five of the nine non-PCD cases, however, no monogenic basis for their situs anomaly was found, which led the authors to consider early environmental or stochastic effects as possible causative factors. 


\section{Systematic Review}

In March 2021, we performed a systematic literature search to address whether visceral situs anomalies have a different prevalence of brain and behavioral asymmetry [85]. The following platforms were searched: Web of Science (indexes: SCI-EXPANDED, SSCI, A\&HCI, CPCI-S, CPCI-SSH, ESCI; range: 1972-2021), PubMed, and Google Scholar. In all cases, we searched for articles with the following strategy 1 . Topic: situs inversus OR heterotaxy; 2. Topic: brain asymmetry OR brain functional asymmetry OR brain structural asymmetry OR behavio(u)ral asymmetry OR hemispheric dominance OR brain laterality; 3. \#1 AND \#2. We obtained a total of 79 records (WoS $n=63$; PubMed $n=11$; Google Scholar $n=5)$. Sixty-nine records were screened after the removal of duplicates. Records on animal research $(n=25)$, genetics $(n=17)$, and medical papers on comorbidities or laterality defects other than situs inversus or heterotaxy $(n=17)$ were excluded. Ten full-text articles were addressed for eligibility. In the references of these articles 7 further (mostly older) studies were identified that reported empirical data on the research question. While this manuscript was under revision, an additional paper on brain asymmetry in fetuses with laterality defects was accepted for publication and added to the review [86]. A total of 18 studies were included in the qualitative synthesis for this systematic review.

Many studies have not described the situs condition of their participants in detail, nor have they differentiated their already small samples of participants into separate categories or explored their genetic background. In the next section, we will summarize the behavioral, brain structural, and brain functional data on atypical asymmetry in participants with situs anomalies or, to be more precise, in participants with situs inversus as almost all brain and behavior-related research in this field has been performed within this subgroup.

\subsection{Handedness in Situs Inversus}

Already in 1836, Sir Thomas Watson remarked that individuals with situs inversus (SI) are no more left-handed than the rest of the population (reported in [87]). This observation was empirically confirmed in several remarkably large-scaled studies of the early to mid20 th century (Table 2) $[88,89]$. These early studies, however, suffer from poor behavioral assessment of handedness and poor etiological description of the situs anomaly. In addition, the reported prevalence of left-handedness around 6-7\% is clearly lower than contemporary estimates of 10\% [90], suggesting that cultural pressure against left-hand use and forced right-handedness may have underestimated natural left-hand preference in these cohorts. As a result, their findings might not provide a clear answer to the question at hand. Then follow two smaller studies based on hospital samples and reporting the low prevalence of non-right-handedness in 6 and 16 SI participants, respectively [91,92]. Unfortunately, very little information on recruitment and SI status or etiology was provided. In both studies the authors concluded that there was little evidence for a relationship between handedness and visceral position. Two later studies that focused on handedness and which recruited quite sizeable cohorts included PCD-related SI participants only. Both studies came to the conclusion that the prevalence of left-handedness in PCD-related SIT is no different from the rest of the population [32,93]. Given the reports of a possible genetic association between relative hand skill and ciliogenesis, typical handedness in PCD-related SIT may seem surprising and has been explained in terms of compensatory mechanism that allow the typical development of handedness to overrule the influence of ciliopathy $[83,84]$. For non-syndromal SI, the issue of handedness is less clear given the paucity or incompleteness of available data. Some information can be gathered from studies that investigated brain functional asymmetry in SI and which predominantly featured non-syndromal cases of SIT (Table 3). Together, these studies report on 22 sporadic cases that were explicitly reported to be free of PCD-symptoms [94-98]. Seventeen of these participants were right-handed, and 5 were left-handed ( $29 \%$ left-handedness). It needs to be remarked that all left-handers were reported by the same study in which 5 out of 9 non-PCD-related SIT had a left-hand preference (55\% left-handedness) [98]. Interestingly, this study also recruited 6 PCD-related SIT cases, only one of which was a left-hander, a result that was in line with previous 
findings on hand preference in PCD-related SIT. Is the seemingly random hand preference in the non-PCD-related SIT participants of the Ghent-cohort an accidental finding? It may well be as none of the other studies even remotely suggested anything of the kind. Future research, preferably in a larger cohort of PCD and non-PCD-related SIT, is necessary to determine if the differential effect of situs inversus on handedness can be replicated. At the same time, the possibility that the etiology of the SI anomaly may differentially influence brain-related asymmetry underlines the importance of providing a detailed description of the SI participants' phenotype and, if possible, also take the genotype into account. 
Table 2. Overview of handedness studies in situs inversus.

\begin{tabular}{|c|c|c|c|c|c|c|}
\hline Author and Year & Sample Size & Situs Anomaly & Etiology & Source & $\begin{array}{l}\text { Percent Left } \\
\text { Handedness }\end{array}$ & $\begin{array}{c}\text { Handedness } \\
\text { Determination }\end{array}$ \\
\hline Cockayne et al., 1938 [88] & 115 & Situs inversus & Not provided & $\begin{array}{l}\text { From literature and the } \\
\text { author's own series; most } \\
\text { included were examined on } \\
\text { account of illness or a } \\
\text { congenital malformation }\end{array}$ & $\begin{array}{l}6.1 \% \mathrm{LH} \text { and } 1.7 \% \\
\text { ambidexter }\end{array}$ & Unknown \\
\hline Torgersen et al., 1950 [89] & $\begin{array}{c}\text { Convenience sample of } \\
160 \text { from a total sample } \\
\text { of } 270\end{array}$ & Situs inversus & Not provided & $\begin{array}{l}\text { Mass X-ray photographs of } \\
\text { the Norwegian population } \\
\text { (200) + additional cases } \\
\text { through hospitals and } \\
\text { municipal health } \\
\text { departments (70) }\end{array}$ & $\begin{array}{l}6.9 \% \text { in SI compared to } \\
3.5 \% \text { in }(715) \text { siblings } \\
\text { and } 5.3 \% \text { in (320) parents }\end{array}$ & $\begin{array}{l}\text { Self-report obtained } \\
\text { from the } \\
\text { individual with SI }\end{array}$ \\
\hline Everett et al., 1963, [91] & $\begin{array}{l}\text { Convenience sample of } 6 \\
\text { from a total sample of } 10\end{array}$ & Situs inversus totalis & Not provided & Hospital records search & $0 \%$ & $\begin{array}{l}\text { Self-report or hospital } \\
\text { records }\end{array}$ \\
\hline Matsumoto et al., 1997 [92] & 16 & Situs inversus & Not provided & Not reported & $6.3 \%$ & $\begin{array}{l}\text { Writing, drawing, } \\
\text { throwing }\end{array}$ \\
\hline $\begin{array}{l}\text { Afzelius and Stenram } \\
\text { et al., } 2006 \text { [32] }\end{array}$ & $\begin{array}{l}\text { Convenience sample of } \\
112 \text { from a total sample } \\
\text { of } 239 \text { PCD patients (105 } \\
\text { PCD-SI and } 134 \text { PCD-SS) }\end{array}$ & Situs inversus & PCD only & $\begin{array}{l}\text { Obtained from contacting } \\
\text { many Swedish clinicians }\end{array}$ & $\begin{array}{c}\text { 12.5\% LH and } 3.6 \\
\text { ambidexter in PCD, } \\
\text { 14.3\% LH in subgroup } \\
\text { with PCD-SI }\end{array}$ & Self-report \\
\hline
\end{tabular}


Table 3. Overview of brain functional asymmetry studies in situs inversus.

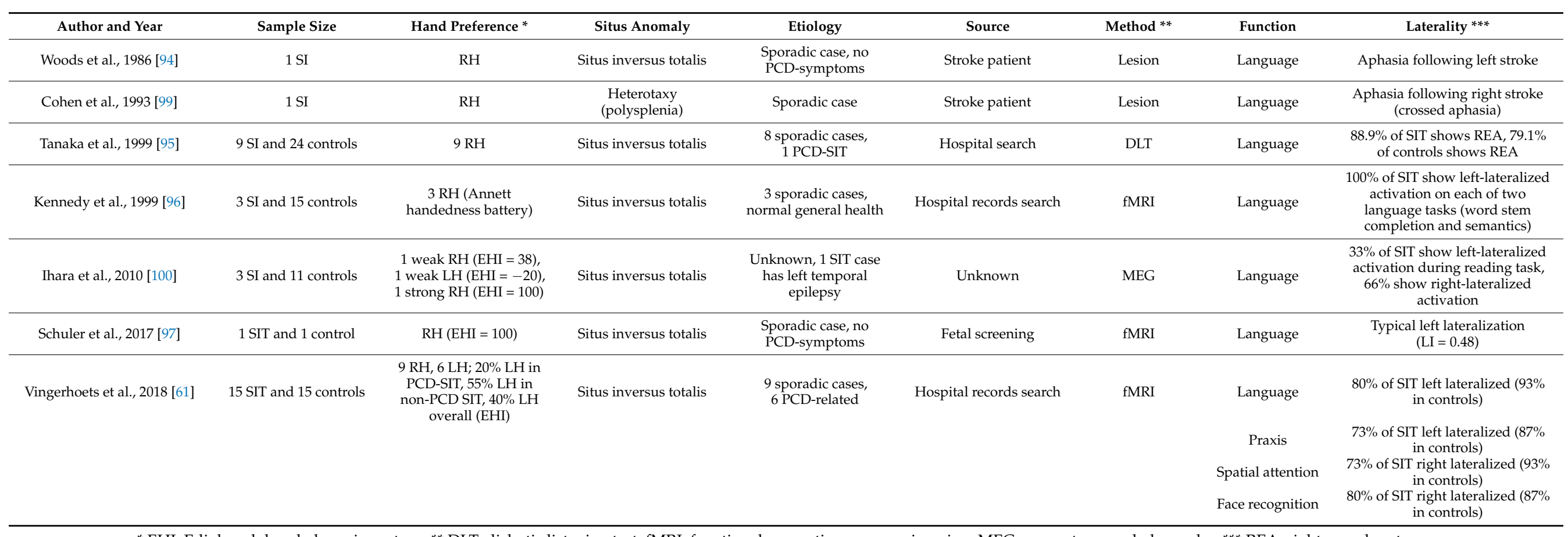

* EHI: Edinburgh handedness inventory; ${ }^{* *}$ DLT: dichotic listening test; fMRI: functional magnetic resonance imaging; MEG: magneto-encephalography; *** REA: right ear advantage. 


\subsection{Brain Functional Asymmetry in Situs Inversus}

As mentioned in the previous paragraph, brain functional asymmetry was predominantly investigated in participants with a non-syndromal manifestation of SI (Table 3). The discussion starts in the late 1980s-early 1990s with the report of two right-handed stroke patients with visceral anomalies, one of which became aphasic following a left hemisphere cerebrovascular lesion [94] while the other, a patient with left isomerism heterotaxy, showed crossed-aphasia after a right hemisphere stroke [99]. More convincing evidence for typical language lateralization came from 9 SIT participants (only one with PCD-related SIT), who performed a dichotic listening paradigm and showed typical right ear advantage in all, but one case [95]. The advent of MRI research provided the opportunity of visualizing neural activation during cognitive tasks. A first fMRI study corroborated Tanaka's dichotic listening findings by showing typical left hemisphere lateralization for language in three non-syndromal SIT participants [96], but a decade later, a second fMRI study reported atypical right hemisphere lateralization for language in two out of three SIT cases [100]. Until now, all studies, including a longitudinal case study that used fMRI [97], had focused on language. Recently, research broadened to other lateralized functions, including praxis, spatial attention, and face recognition, in an fMRI study of 15 SIT participants, of which 6 had PCD-related SIT, and 9 had non-PCD-related SIT [61]. While $80 \%$ of this cohort had left hemisphere language dominance, suggesting generally typical language lateralization, a control group matched for handedness showed $93 \%$ leftward lateralization. The same trend was found for the three other tested functions that all showed more typical asymmetry in the matched controls compared to the SIT participants. The authors concluded that atypical functional segregation, that is, the likelihood that brain functional organization does not show the typical population pattern, is more frequent in SIT participants. No obvious difference in the level of deviation from typical functional segregation was observed between PCD and non-PCD-related SIT, but the small sample size limits proper statistical comparison. It can be argued that results on functional lateralization have been influenced by the unexpectedly high number of left-handers in this sample as left-handers have a higher prevalence of atypical functional lateralization [2], but atypical lateralization occurred equally frequently in the right-handed SIT participants. Together, the available data suggest that, while most people with SIT will show typical patterns of functional asymmetry, atypical lateralization of language and other asymmetric functions may be more frequent in SIT. It remains to be determined whether this is a general trend or associated with specific etiological characteristics.

\subsection{Brain Structural Asymmetry in Situs Inversus}

An overview of studies reporting on brain structural asymmetry in SI is provided in Table 4. If there is one consistent finding on brain asymmetry in SI, it is the observation that their cerebral torque is generally reversed than the typical human population bias. The cerebral or "Yakovlevian" torque is a gross anatomical and morphologically complex characteristic [101] that refers to an anti-clockwise twist of the brain about the ventraldorsal axis. It is most often described in terms of its petalia, whereby the right frontal pole protrudes anteriorly to the right frontal pole, and the left occipital pole protrudes posteriorly to the right occipital pole. Typical petalia asymmetry is observed in $44 \%$ of modern human brains [102] and appears to be absent in non-human primates [101]. Reversed petalia were reported in 15 out of 23 SIT participants (65\%), most of which were sporadic cases. Again, a possible distinction arises between syndromal and non-syndromal SIT as a recent study documented complete reversal of the petalia in 7 out of 9 non-PCD-related SIT participants $(78 \%)$ and in none of the 6 PCD-related SIT participants [98]. It remains to be confirmed whether the reversed cerebral torque pairs with the reversal of intracranial vasculature and bony landmarks as suggested by one post-mortem study [103]. If it does, it would be an important argument for a link between different brain morphological asymmetries and a link between lateralized gradients of brain structural and visceral development. 
Table 4. Overview of studies on brain structural asymmetry in situs inversus.

\begin{tabular}{|c|c|c|c|c|c|c|c|c|c|c|}
\hline Author and Year & Sample Size & Hand Preference & Situs Anomaly & Etiology & Source & Method * & $\begin{array}{l}\text { Cerebral Torque } \\
\text { (Petalia) }\end{array}$ & $\begin{array}{c}\text { Planum } \\
\text { Temporale }\end{array}$ & Sylvian Fissure & Other ** \\
\hline $\begin{array}{l}\text { Kennedy et al., } \\
1999[96]\end{array}$ & $\begin{array}{l}3 \text { SIT and } 15 \\
\text { controls }\end{array}$ & $\mathrm{RH}(\mathrm{AHB}=1.24)$ & $\begin{array}{l}\text { Situs inversus } \\
\text { totalis }\end{array}$ & $\begin{array}{c}\text { Sporadic cases, } \\
\text { normal general } \\
\text { health }\end{array}$ & $\begin{array}{l}\text { Hospital records } \\
\text { search }\end{array}$ & MRI & Reversed in all SIT & $\begin{array}{c}\text { Volume } \mathrm{L}>\mathrm{R} \text { in } \\
2 \mathrm{SIT} \text { and } \mathrm{R}>\mathrm{L} \text { in } \\
\text { one SIT }\end{array}$ & $\begin{array}{c}\text { Higher } \mathrm{R}>\mathrm{L} \text { in } \\
2 \mathrm{SIT}\end{array}$ & \\
\hline $\begin{array}{l}\text { Tubbs et al., } \\
2003 \text { [103] }\end{array}$ & 1 SIT & Unknown & $\begin{array}{l}\text { Situs inversus } \\
\text { totalis }\end{array}$ & $\begin{array}{l}\text { Unknown, died } \\
\text { from “natural } \\
\text { causes" }\end{array}$ & Unknown & Autopsy & Reversed & & Higher $L>R$ & $\begin{array}{l}\text { Reversed intracranial } \\
\text { vasculature }\end{array}$ \\
\hline $\begin{array}{l}\text { Thara et al., } \\
2010[100]\end{array}$ & $\begin{array}{l}3 \text { SIT and } 11 \\
\text { controls }\end{array}$ & $2 \mathrm{RH}, 1 \mathrm{LH}$ & $\begin{array}{l}\text { Situs inversus } \\
\text { totalis }\end{array}$ & $\begin{array}{c}\text { Unknown, } 1 \text { SIT } \\
\text { has temporal lobe } \\
\text { epilepsy }\end{array}$ & Unknown & MRI & Reversed in all SIT & $\begin{array}{l}\text { Volume } \mathrm{L}>\mathrm{R} \text { in } \\
3 \text { SIT }\end{array}$ & & $\begin{array}{l}\text { IFG volume } \mathrm{L}>\mathrm{R} \text { in } \\
2 \mathrm{SIT}, \mathrm{R}>\mathrm{L} \text { in1 } \mathrm{SIT}\end{array}$ \\
\hline $\begin{array}{l}\text { Leroy et al., } \\
2015 \text { [104] }\end{array}$ & $\begin{array}{c}6 \text { SIT and } 95 \\
\text { controls (48 RH) }\end{array}$ & $5 \mathrm{RH}, 1 \mathrm{LH}$ & $\begin{array}{l}\text { Situs inversus } \\
\text { totalis }\end{array}$ & $\begin{array}{l}\text { Cases from the } \\
\text { Kennedy et al. and } \\
\text { Ihara et al. studies }\end{array}$ & $\begin{array}{l}\text { Cases from the } \\
\text { Kennedy et al. and } \\
\text { Ihara et al. studies }\end{array}$ & MRI & & & & $\begin{array}{l}\text { STS deeper on right } \\
\text { (typical) }\end{array}$ \\
\hline $\begin{array}{l}\text { Schuler et al., } \\
2017 \text { [97] }\end{array}$ & 1 SIT and 1 control & $\mathrm{RH}(\mathrm{EHI}=100)$ & $\begin{array}{l}\text { Situs inversus } \\
\text { totalis }\end{array}$ & $\begin{array}{l}\text { Sporadic case, no } \\
\text { PCD-symptoms }\end{array}$ & Fetal screening & MRI & Reversed in SIT & $\begin{array}{c}\text { Absent } \\
\text { asymmetry in SIT }\end{array}$ & & $\begin{array}{c}\text { STS deeper on right } \\
\text { (typical) }\end{array}$ \\
\hline $\begin{array}{l}\text { Vingerhoets et al., } \\
2018 \text { [98] and } \\
\text { Mannaert et al., } \\
2019 \text { [105] }\end{array}$ & $\begin{array}{l}15 \text { SIT and } \\
15 \text { controls }\end{array}$ & $9 \mathrm{RH}, 6 \mathrm{LH}$ & $\begin{array}{l}\text { Situs inversus } \\
\text { totalis }\end{array}$ & $\begin{array}{l}9 \text { sporadic cases, } \\
6 \text { PCD-related }\end{array}$ & $\begin{array}{l}\text { Hospital records } \\
\text { search }\end{array}$ & MRI & $\begin{array}{c}\text { Reversed in } 78 \% \\
\text { of non-PCD SIT } \\
\text { and in } 0 \% \text { of PCD } \\
\text { SIT }\end{array}$ & $\begin{array}{l}\text { Not different from } \\
\text { controls }\end{array}$ & Same as controls & $\begin{array}{c}\text { IFG volume same as } \\
\text { controls; } \\
\text { Heschl's gyrus and } \\
\text { anterior insula volume } \\
\text { same as controls; } \\
\text { Arcuate fasciculus } \\
\text { volume same as } \\
\text { controls; } \\
\text { Uncinate fasciculus } \\
\text { lower volume in SIT } \\
\text { than controls }\end{array}$ \\
\hline $\begin{array}{l}\text { Kienast et al., } \\
2021 \text { [86] }\end{array}$ & $\begin{array}{l}5 \text { fetuses with } \\
\text { ciliopathies and } \\
21 \text { fetuses with } \\
\text { laterality defects; } \\
26 \text { age-matched } \\
\text { controls }\end{array}$ & Not applicable & $\begin{array}{c}4 \text { SIT; } 8 \\
\text { dextrocardia; } \\
4 \text { situs ambiguus; } \\
5 \text { situs inversus } \\
\text { abdominalis }\end{array}$ & $\begin{array}{l}\text { Prenatal diagnosis } \\
\text { reports }\end{array}$ & $\begin{array}{l}\text { Hospital records } \\
\text { search }\end{array}$ & MRI & & & & $\begin{array}{l}\text { Perisylvian fetal } \\
\text { patterns and } \\
\text { asymmetry indices do } \\
\text { not differ between } \\
\text { cases with laterality } \\
\text { defects, ciliopathies, } \\
\text { and normal controls }\end{array}$ \\
\hline
\end{tabular}

* MRI: magnetic resonance imaging; ** IFG: inferior frontal gyrus; STS: superior temporal sulcus. 
No systematic reversals in other structural brain asymmetries have been reported in SI. Alleged language-related markers like the planum temporale, Sylvian fissure, inferior frontal gyrus, depth of the superior temporal sulcus, and the arcuate fasciculus show the same variability and directional bias as the general population. The available data are scarce, though, and the discovery of more subtle effects or between SIT-type differences awaits further research.

\section{Discussion}

The low prevalence and substantial phenotypical variability of human visceral laterality anomalies postpone consensus on clear classification criteria for subgroup determination. Still, two broad categories of anomalies are generally distinguished, situs inversus characterized by a complete or near-complete mirror reversal of typical visceral asymmetry, and heterotaxy described as a duplication of one of either asymmetric sides. Both phenotype categories are believed to result from different deficits in the complex developmental cascade of visceral left-right differentiation, but the exact causal implications for each step and each genetic mutation in that process remain to be elucidated. The same is true for the brain. While the prevalence of nonconventional brain organization is roughly 100 times more frequent than atypical visceral organization, it is more difficult to assess, and data are scarce. However, here too, two main categories of unconventional brain organization are advanced, reversed functional segregation presenting as a mirror image of the usual hemispheric task division, and atypical functional segregation characterized by functional crowding.

The substantial difference in the prevalence of atypical visceral and brain organization also brings the effect of evolutionary canalization to mind, the increased resistance of a trait to genetic and environmental perturbations over evolutionary time. Left-sided heart anatomy is a preserved trait in all living vertebrates, but the incidence of spontaneous reversal declines throughout vertebrate evolution from $5 \%$ in fish, $1-2 \%$ in amphibians, $0.1 \%$ in mammals, and $0.01 \%$ in humans [9]. Explanations for the evolutionary increase in canalization include increased predictability of symmetry breaking by cilia-controlled nodal flow or the more stable conditions of the placental environment [9]. Cladistic estimates of reversals in brain organization are not available, but the concept of evolutionary canalization may provide an interesting venue to explore the origin and timing of brain structural and functional asymmetries in humans by comparing prevalence measures of atypical laterality.

Apart from similarities in the overall appearance of the main phenotype subgroups of visceral and brain laterality anomalies, we should keep in mind that the visceral and neural systems serve fundamentally different biological functions and that the reasons for developing asymmetry in each system are likely to be dissimilar. Nevertheless, selfsame basic mechanisms for left-right differentiation may be employed by both systems to generate and/or propel asymmetry [9]. This possibility is hinted at by some mutant lines in vertebrate species that appear to align atypical visceral with atypical brain structural asymmetry and which also appears to impact their behavioral asymmetries $[3,5]$. One way to explore such a relation in humans is to investigate and compare the developmental cascades of visceral and brain laterality and scrutinize the molecular genetics underlying both mechanisms for biological links or similarities. The road toward asymmetry appears very complex and much of it, particularly concerning the brain, remains to be discovered.

An alternative way to explore possible relations lies in the direct comparison of phenotypes by investigating brain and behavioral asymmetries in individuals with situs anomalies. Delineation of atypical manifestations could provide molecular genetics with more specific targets to find associations between the developmental cascades of visceral and brain asymmetry. While this approach is hampered by the low prevalence of situs anomalies and the laborious assessment of brain asymmetries, several studies have contributed to this endeavor. However, samples are often small, and the range of phenotypes is restricted or poorly defined. 
Most, if not all, studies on behavioral and brain asymmetry in situs anomalies focused on situs inversus (totalis). Probable reasons for this selective approach are the anticipation of more straightforward results and the better medical condition of participants with situs inversus compared to those with heterotaxy. In general, the studies appear to agree that situs inversus in humans is not inseparably associated with a reversal of brain and behavioral asymmetries as seen in some other species. On the contrary, most people with situs inversus seem to present with typical patterns of hemispheric specialization, although a higher prevalence of functional crowding in this group remains a possibility. At the same time, the findings hint at some more subtle effects that distinguish between types of situs inversus with different etiologies. More in particular, in PCD-related syndromal situs inversus, handedness and probably also brain torque reveal the same laterality bias as the general population. This finding can be taken to suggest that nodal ciliopathy and the eventually reversed subsequent molecular cascade that gives rise to visceral laterality has only little effect on hand preference and gross brain morphology. By contrast, situs inversus caused by non-ciliary, perhaps earlier, factors does seem to be accompanied by a reversal of the brain torque. This finding is reported by several independent studies from North America, Japan, and Europe and indeed hints at a possible relation between human visceral asymmetry and the asymmetrical shape of the brain organ. A possible venue to investigate a direct relation between both manifestations of directional asymmetry in humans would be to determine signed fluctuating asymmetry of the visceral and brain torque modules in a sample of humans, which do not necessarily need to have a visceral anomaly [8]. To corroborate and extend findings on brain asymmetry in visceral anomalies, future research should provide detailed phenotypical information of participants supplemented by genetic data if possible. Ideally, a consensus should be reached on core information to be reported that will allow open science and meta-analytic initiatives to gather larger samples of participants with situs anomalies and further understand possible interactions between human visceral and brain asymmetry.

Author Contributions: G.V. wrote the manuscript with support from R.G. and H.V. All authors have read and agreed to the published version of the manuscript.

Funding: This research received no external funding.

Institutional Review Board Statement: Not applicable (review).

Informed Consent Statement: Not applicable.

Data Availability Statement: Not applicable.

Conflicts of Interest: The authors declare no conflict of interest.

\section{Glossary}

Anterior neural ridge: The anterior neural ridge is a region in the neural plate and later neural tube, which secretes signaling molecules essential for developing the forebrain. Antisymmetry: Dextral and sinistral forms are equally present within a population. Atypical hemispheric functional segregation: Phenotype of hemispheric functional segregation in which the typical left-right segregation is lost due to one or more functions showing atypical dominance, while other functions do not. Autosomal dominant disorder: A pattern of inheritance in which an affected individual has one copy of a mutant gene and one normal gene on a pair of autosomal (one of the numbered, non-sex) chromosomes. Autosomal recessive disorder: A pattern of inheritance in which an affected individual requires two copies of a mutant gene on a pair of autosomal (one of the numbered, non-sex) chromosomes. Behavioral asymmetry: Left-right difference in behavior, like hand or foot preference, or the increased probability to retain words presented to the right ear versus those presented to the left ear. Brain asymmetry: Left-right differences in functional or structural (anatomical) characteristics between the two hemispheres. Canalization (evolutionary canalization): Increased resistance of an established trait for genetic or en- 
vironmental perturbations over evolutionary time. Cascade capture: The recruitment of genes or gene cascades for another duty. Cilium/Cilia: Small hair-like organelles that protrude from the larger cell body. Cilia can be motile or non-motile. Non-motile cilia serve as sensory organelles, much like a cellular antenna. Cells of the transient primitive node have singular motile cilia known as nodal cilia, critical for the establishment of left to right body asymmetry. Ciliogenesis: The building of the cell's cilium/cilia. Defects in ciliogenesis can lead to numerous human diseases related to non-functioning cilia (ciliopathies). Ciliary motility: The ability of some cilia types to produce motion by a molecular motor that drives its beating. Motile cilia have a function in the transport of fluids over the surface of cells. Dextrocardia: A rare congenital condition in which the heart's apex is located on the right side of the body. Directional asymmetry: Most individuals in a population are asymmetrical in the same direction (population bias). Floor plate: Located on the ventral midline of the embryonic neural tube, the floor plate is a glial structure that serves as an organizer to ventralize tissues in the embryo as well as to guide neuronal positioning and differentiation along the dorsoventral axis of the neural tube. Fluctuating asymmetry: The amount of deviation from perfect bilateral symmetry as reflected by small differences between the left and the right sides due to random errors in the individual development. fMRI: Functional magnetic resonance imaging is a non-invasive technique to measure and map changes in the brain's blood flow that coincide with brain activity. Forebrain (prosencephalon): The rostral (forward-most) portion of the brain that will develop into the diencephalon (thalamus, hypothalamus, subthalamus, and epithalamus) and the telencephalon, which develops into the cerebrum. fTCD: Functional transcranial Doppler ultrasonography is a non-invasive technique to measure changes in the blood flow velocity of the basal segments of the cerebral arteries that coincide with brain activity. Gastrulation: A phase in early embryonic development during which the single-layered hollow sphere of cells (blastula) is reorganized into a multilayered structure (gastrula). By the end of gastrulation, the embryo has begun differentiation to establish distinct cell lineages and set up the basic axes of the body. Genetic assimilation: An alternative mechanism of variation (compared to mutations, in which genotype precedes phenotype) in which developmental plasticity creates novel phenotypes before heritable variation exists (phenotype precedes genotype). Genetic control over the new phenotype arises later through random mutations. Genotype: The particular type and arrangement of genes of an organism. Hemispheric dominance: The phenomenon that cognitive processes tend to be specialized to one side of the brain or the other, as demonstrated by aphasia following left hemisphere lesions and spatial neglect following right hemisphere lesions in most people. Hemispheric functional segregation: The division of labor in cognitive tasks between both hemispheres. In humans, hemispheric functional segregation shows a strong population bias toward prototypical segregation in which the left hemisphere is known to be dominant for language, fine motor control, and praxis (learned gestures), whereas the right hemisphere supports spatial attention, face recognition and prosody of speech. Heterotaxy: The loss of typical left-right laterality in the arrangement of the visceral organs along the superior-inferior axis, also referred to as situs ambiguus. Kartagener syndrome: A rare, autosomal recessive genetic ciliary disorder comprising the triad of situs inversus, chronic sinusitis, and bronchiectasis. Lateral plate mesoderm: A type of mesoderm that is found at the periphery of the embryo. Lefty: A class of proteins related to the superfamily of growth factors that play a role in left-right asymmetry determination of organ systems during development. Levocardia: A condition where the heart is on the left (typical) side of the thoracic cavity. Neural tube: The embryonic precursor to the central nervous system, which is made up of the brain and spinal cord. Neurulation: The folding process in vertebrate embryos, which includes the transformation of the neural plate into the neural tube. Nodal: A protein that is encoded by the human NODAL gene, which belongs to the transforming growth factor-beta superfamily. It is involved in cell differentiation in early embryogenesis, playing a key role in signal transfer from the primitive node, in the anterior primitive streak, to the lateral plate mesoderm. Nodal flow: The (leftward) movement of fluid at the prim- 
itive node caused by ciliary movement and taken to be a central process in symmetry breaking on the left-right axis. Ortholog: A homologous gene found in different species related by linear descent. Phenotype: The sum of an organism's observable characteristics or traits. Pitx2: A protein that in humans is encoded by the PITX2 gene. This protein acts as a transcription factor and is involved in developing the eye, tooth and abdominal organs. Pleiotropy: Occurs when one gene influences two or more seemingly unrelated phenotypic traits. Mutation in a pleiotropic gene may affect several traits simultaneously. Primitive node: The organizer for gastrulation in the vertebrate embryo. Primary ciliary dyskinesia: A rare, ciliopathic, genetically heterogeneous disorder that causes defects in the action of cilia lining the respiratory tract (lower and upper, sinuses, Eustachian tube, middle ear), fallopian tube, and flagellum of sperm cells. Reversed typical hemispheric functional segregation: Phenotype of hemispheric functional segregation in which the left-right laterality of functions is reversed than the typical organization seen in the population. While the habitual functional segregation is maintained, the phenotype is a mirror image of the usual functional brain organization. Roof plate: An embryonic organizing center consisting of specialized glial cells that occupy the dorsal midline of the vertebrate neural tube. The roof plate generates morphogenic signals along the length of the neuraxis, which control the specification and differentiation of dorsal neuronal cell types. Shh: Sonic hedgehog (Shh) is a protein that, in humans, is encoded by the SHH gene. Shh plays a key role in developing many animals. In vertebrates, it is involved in organogenesis. Signaltransducing pathway: Signal transduction is the process by which a chemical or physical signal is transmitted through a cell as a series of molecular events, which ultimately results in a cellular response. The changes give rise to a chain of biochemical events known as a signaling pathway. Situs ambiguus: Medical term referring to a loss of the typical left-right positioning of thoracic and abdominal organs, also called heterotaxy. Situs inversus (totalis): Medical term referring to a reversal of the typical position of thoracic and abdominal organs. Situs solitus: Medical term referring to the typical position of thoracic and abdominal organs. Transcriptomics: The study of the transcriptome-the complete set of RNA transcripts that are produced by the genome- - using high-throughput methods, such as microarray analysis. Typical hemispheric functional segregation: Phenotype of hemispheric functional segregation that, due to a population bias, is most common in the human population. Visceral asymmetry: Refers to the asymmetry in left-right positioning of thoracic and abdominal organs.

\section{References}

1. Hamada, H.; Meno, C.; Watanabe, D.; Saijoh, Y. Establishment of vertebrate left-right asymmetry. Nat. Rev. Genet. 2002,3 , $103-113$. [CrossRef]

2. Vingerhoets, G. Phenotypes in hemispheric functional segregation? Perspectives and challenges. Phys. Life Rev. 2019. [CrossRef]

3. Long, S.; Ahmad, N.; Rebagliati, M. The zebrafish nodal-related gene southpaw is required for visceral and diencephalic left-right asymmetry. Development 2003, 130, 2303-2316. [CrossRef]

4. Concha, M.L.; Burdine, R.D.; Russell, C.; Schier, A.F.; Wilson, S.W. A nodal signaling pathway regulates the laterality of neuroanatomical asymmetries in the zebrafish forebrain. Neuron 2000, 28, 399-409. [CrossRef]

5. Wehrmaker, A. Right-Left Asymmetry and Situs Iversus in Triturus alpestris. Wilhem Roux' Arch. Entwickl. Org. 1969, 163, 1-32. [CrossRef] [PubMed]

6. Concha, M.L.; Wilson, S.W. Asymmetry in the epithalamus of vertebrates. J. Anat. 2001, 199, 63-84. [CrossRef] [PubMed]

7. Barth, K.A.; Miklosi, A.; Watkins, J.; Bianco, I.H.; Wilson, S.W.; Andrew, R.J. fsi zebrafish show concordant reversal of laterality of viscera, neuroanatomy, and a subset of behavioral responses. Curr. Biol. 2005, 15, 844-850. [CrossRef] [PubMed]

8. Klingenberg, C.P. Developmental instability as a research tool: Using patterns of fluctuating asymmetry to infer the developmental origins of morphological integration. In Developmental Stability: Causes and Consequences; Polak, M., Ed.; Oxford University Press: Oxford, UK, 2003; pp. 427-442.

9. Palmer, A.R. Symmetry breaking and the evolution of development. Science 2004, 306, 828-833. [CrossRef]

10. Nakamura, T.; Hamada, H. Left-right patterning: Conserved and divergent mechanisms. Development 2012, 139, 3257-3262. [CrossRef]

11. Aylsworth, A.S. Clinical aspects of defects in the determination of laterality. Am. J. Med. Genet. 2001, 101, 345-355. [CrossRef] 
12. Lin, A.E.; Krikov, S.; Riehle-Colarusso, T.; Frias, J.L.; Belmont, J.; Anderka, M.; Geva, T.; Getz, K.D.; Botto, L.D.; Prevention, N.B.D. Laterality Defects in the National Birth Defects Prevention Study (1998-2007): Birth Prevalence and Descriptive Epidemiology. Am. J. Med. Genet. Part A 2014, 164, 2581-2591. [CrossRef]

13. Houyel, L.; Khoshnood, B.; Anderson, R.H.; Lelong, N.; Thieulin, A.C.; Goffinet, F.; Bonnet, D.; Grp, E.S. Population-based evaluation of a suggested anatomic and clinical classification of congenital heart defects based on the International Paediatric and Congenital Cardiac Code. Orphanet J. Rare Dis. 2011, 6. [CrossRef]

14. Casey, B. Two rights make a wrong: Human left-right malformations. Hum. Mol. Genet. 1998, 7, 1565-1571. [CrossRef]

15. Kosaki, K.; Casey, B. Genetics of human left-right axis malformations. Semin. Cell Dev. Biol. 1998, 9, 89-99. [CrossRef] [PubMed]

16. Lin, A.E.; Ticho, B.S.; Houde, K.; Westgate, M.N.; Holmes, L.B. Heterotaxy: Associated conditions and hospital-based prevalence in newborns. Genet. Med. 2000, 2, 157-172. [CrossRef] [PubMed]

17. Evans, W.N.; Acherman, R.J.; Restrepo, H. Heterotaxy in Southern Nevada: Prenatal Detection and Epidemiology. Pediatric Cardiol. 2015, 36, 930-934. [CrossRef]

18. Peeters, H.; Devriendt, K. Human laterality disorders. Eur. J. Med. Genet. 2006, 49, 349-362. [CrossRef] [PubMed]

19. Sutherland, M.J.; Ware, S.M. Disorders of Left-Right Asymmetry: Heterotaxy and Situs Inversus. Am. J. Med. Genet. Part C Semin. Med. Genet. 2009, 151c, 307-317. [CrossRef]

20. Schmutzer, K.J.; Linde, L.M. Situs Inversus Totalis Associated with Complex Cardiovascular Anomalies. Am. Heart J. 1958, 56, 761-768. [CrossRef]

21. Chen, W.; Guo, Z.; Qian, L.; Wang, L. Comorbidities in situs inversus totalis: A hospital-based study. Birth Defects Res 2020, 112, 418-426. [CrossRef]

22. Kennedy, M.P.; Omran, H.; Leigh, M.W.; Dell, S.; Morgan, L.; Molina, P.L.; Robinson, B.V.; Minnix, S.L.; Olbrich, H.; Severin, T.; et al. Congenital heart disease and other heterotaxic defects in a large cohort of patients with primary ciliary dyskinesia. Circulation 2007, 115, 2814-2821. [CrossRef]

23. Gabriel, G.C.; Lo, C.W. Left-right patterning in congenital heart disease beyond heterotaxy. Am. J. Med. Genet. Part C Semin. Med. Genet. 2020, 184, 90-96. [CrossRef]

24. Deng, H.; Xia, H.; Deng, S. Genetic basis of human left-right asymmetry disorders. Expert Rev. Mol. Med. 2015, 16, e19. [CrossRef]

25. Postema, M.C.; Carrion-Castillo, A.; Fisher, S.E.; Vingerhoets, G.; Francks, C. The genetics of situs inversus without primary ciliary dyskinesia. Sci. Rep. 2020, 10. [CrossRef]

26. Lucas, J.S.; Burgess, A.; Mitchison, H.M.; Moya, E.; Williamson, M.; Hogg, C.; Serv, N.P. Diagnosis and management of primary ciliary dyskinesia. Arch. Dis. Child. 2014, 99, 850-856. [CrossRef]

27. Afzelius, B.A. Human Syndrome Caused by Immotile Cilia. Science 1976, 193, 317-319. [CrossRef]

28. Bartoloni, L.; Blouin, J.L.; Pan, Y.Z.; Gehrig, C.; Maiti, A.K.; Scamuffa, N.; Rossier, C.; Jorissen, M.; Armengot, M.; Meeks, M.; et al. Mutations in the DNAH11 (axonemal heavy chain dynein type 11) gene cause one form of situs inversus totalis and most likely primary ciliary dyskinesia. Proc. Natl. Acad. Sci. USA 2002, 99, 10282-10286. [CrossRef]

29. Leigh, M.W.; Pittman, J.E.; Carson, J.L.; Ferkol, T.W.; Dell, S.D.; Davis, S.D.; Knowles, M.R.; Zariwala, M.A. Clinical and genetic aspects of primary ciliary dyskinesia/Kartagener syndrome. Genet Med. 2009, 11, 473-487. [CrossRef]

30. Zariwala, M.A.; Omran, H.; Ferkol, T.W. The emerging genetics of primary ciliary dyskinesia. Proc. Am. Thorac. Soc. 2011, 8, 430-433. [CrossRef]

31. Bisgrove, B.W.; Yost, H.J. The roles of cilia in developmental disorders and disease. Development 2006, 133, 4131-4143. [CrossRef]

32. Afzelius, B.A.; Stenram, U. Prevalence and genetics of immotile-cilia syndrome and left-handedness. Int. J. Dev. Biol. 2006, 50, 571-573. [CrossRef]

33. Bush, A.; Cole, P.; Hariri, M.; Mackay, I.; Phillips, G.; O'Callaghan, C.; Wilson, R.; Warner, J.O. Primary ciliary dyskinesia: Diagnosis and standards of care. Eur. Respir. J. 1998, 12, 982-988. [CrossRef]

34. Kartagener, M. Zur Pathogenese der Bronchiektasien bei Situs viscerum inversus. Beiträge Klin. Tuberk. 1933, 83, 489-501. [CrossRef]

35. Engesaeth, V.G.; Warner, J.O.; Bush, A. New Associations of Primary Ciliary Dyskinesia Syndrome. Pediatric Pulmonol. 1993, 16, 9-12. [CrossRef] [PubMed]

36. Noone, P.G.; Bali, D.; Carson, J.L.; Sannuti, A.; Gipson, C.L.; Ostrowski, L.E.; Bromberg, P.A.; Boucher, R.C.; Knowles, M.R. Discordant organ laterality in monozygotic twins with primary ciliary dyskinesia. Am. J. Med. Genet. 1999, 82, 155-160. [CrossRef]

37. Vandenberg, L.N.; Levin, M. A unified model for left-right asymmetry? Comparison and synthesis of molecular models of embryonic laterality. Dev. Biol. 2013, 379, 1-15. [CrossRef] [PubMed]

38. Komatsu, Y.; Mishina, Y. Establishment of left-right asymmetry in vertebrate development: The node in mouse embryos. Cell. Mol. Life Sci. 2013, 70, 4659-4666. [CrossRef] [PubMed]

39. Hirokawa, N.; Tanaka, Y.; Okada, Y. Left-Right Determination: Involvement of Molecular Motor KIF3, Cilia, and Nodal Flow. Cold Spring Harb. Perspect. Biol. 2009, 1. [CrossRef]

40. Vandenberg, L.N.; Levin, M. Far From Solved: A Perspective on What We Know About Early Mechanisms of Left-Right Asymmetry. Dev. Dyn. 2010, 239, 3131-3146. [CrossRef] [PubMed]

41. Basu, B.; Bruedner, M. Cilia: Multifunctional Organelles at the Center of Vertebrate Left-Right Asymmetry. Ciliary Funct. Mamm. Dev. 2008, 85, 151-174. [CrossRef] 
42. Nonaka, S.; Shiratori, H.; Saijoh, Y.; Hamada, H. Determination of left-right patterning of the mouse embryo by artificial nodal flow. Nature 2002, 418, 96-99. [CrossRef] [PubMed]

43. Watanabe, D.; Saijoh, Y.; Nonaka, S.; Sasaki, G.; Ikawa, Y.; Yokoyama, T.; Hamada, H. The left-right determinant Inversin is a component of node monocilia and other 9+0 cilia. Development 2003, 130, 1725-1734. [CrossRef]

44. Okada, Y.; Nonaka, S.; Tanaka, Y.; Saijoh, Y.; Hamada, H.; Hirokawa, N. Abnormal nodal flow precedes situs inversus in iv and inv mice. Mol. Cell 1999, 4, 459-468. [CrossRef]

45. Smith, D.J.; Montenegro-Johnson, T.D.; Lopes, S.S. Symmetry-Breaking Cilia-Driven Flow in Embryogenesis. Annu. Rev. Fluid Mech. 2019, 51, 105-128. [CrossRef]

46. Rogers, L.J.; Zucca, P.; Vallortigara, G. Advantages of having a lateralized brain. Proc. R. Soc. B Biol. Sci. 2004, 271, S420-S422. [CrossRef] [PubMed]

47. Vallortigara, G.; Rogers, L.J.; Bisazza, A. Possible evolutionary origins of cognitive brain lateralization. Brain Res. Rev. 1999, 30, 164-175. [CrossRef]

48. Cai, Q.; Van der Haegen, L.; Brysbaert, M. Complementary hemispheric specialization for language production and visuospatial attention. Proc. Natl. Acad. Sci. USA 2013, 110, E322-E330. [CrossRef]

49. Vingerhoets, G.; Alderweireldt, A.S.; Vandemaele, P.; Cai, Q.; Van der Haegen, L.; Brysbaert, M.; Achten, E. Praxis and language are linked: Evidence from co-lateralization in individuals, with atypical language dominance. Cortex 2013, 49, 172-183. [CrossRef]

50. Gerrits, R.; Van der Haegen, L.; Brysbaert, M.; Vingerhoets, G. Laterality for recognizing written words and faces in the fusiform gyrus covaries with language dominance. Cortex J. Devoted Study Nerv. Syst. Behav. 2019, 117, 196-204. [CrossRef]

51. Gerrits, R.; Verhelst, H.; Vingerhoets, G. Mirrored brain organization: Statistical anomaly or reversal of hemispheric functional segregation bias? Proc. Natl. Acad. Sci. USA 2020, 117, 14057-14065. [CrossRef]

52. Bryden, M.P.; Hecaen, H.; Deagostini, M. Patterns of Cerebral Organization. Brain Lang. 1983, 20, 249-262. [CrossRef]

53. McNeely, H.E.; Parlow, S.E. Complementarity of linguistic and prosodic processes in the intact brain. Brain Lang. 2001, 79, 473-481. [CrossRef]

54. Floel, A.; Buyx, A.; Breitenstein, C.; Lohmann, H.; Knecht, S. Hemispheric lateralization of spatial attention in right- and left-hemispheric language dominance. Behav. Brain Res. 2005, 158, 269-275. [CrossRef]

55. Whitehouse, A.J.O.; Bishop, D.V.M. Hemispheric division of function is the result of independent probabilistic biases. Neuropsychologia 2009, 47, 1938-1943. [CrossRef]

56. Badzakova-Trajkov, G.; Haberling, I.S.; Roberts, R.P.; Corballis, M.C. Cerebral Asymmetries: Complementary and independent processes. PLoS ONE 2010, 5, e9682. [CrossRef]

57. Rosch, R.E.; Bishop, D.V.M.; Badcock, N.A. Lateralised visual attention is unrelated to language lateralisation, and not influenced by task difficulty-A functional transcranial Doppler study. Neuropsychologia 2012, 50, 810-815. [CrossRef]

58. Groen, M.A.; Whitehouse, A.J.O.; Badcock, N.A.; Bishop, D.V.M. Does cerebral lateralization develop? A study using functional transcranial Doppler ultrasound assessing lateralization for language production and visuospatial memory. Brain Behav. 2012, 2, 256-269. [CrossRef]

59. Zago, L.; Petit, L.; Mellet, E.; Jobard, G.; Crivello, F.; Joliot, M.; Mazoyer, B.; Tzourio-Mazoyer, N. The association between hemispheric specialization for language production and for spatial attention depends on left-hand preference strength. Neuropsychologia 2016, 93, 394-406. [CrossRef]

60. Francks, C. Exploring human brain lateralization with molecular genetics and genomics. Ann. N. Y. Acad. Sci. 2015, 1359, 1-13. [CrossRef]

61. Vingerhoets, G.; Gerrits, R.; Bogaert, S. Atypical brain functional segregation is more frequent in situs inversus totalis. Cortex 2018, 106, 12-25. [CrossRef]

62. Mazoyer, B.; Zago, L.; Jobard, G.; Crivello, F.; Joliot, M.; Perchey, G.; Mellet, E.; Petit, L.; Tzourio-Mazoyer, N. Gaussian Mixture Modeling of Hemispheric Lateralization for Language in a Large Sample of Healthy Individuals Balanced for Handedness. PLoS ONE 2014, 9, e101165. [CrossRef]

63. Zago, L.; Herve, P.Y.; Genuer, R.; Laurent, A.; Mazoyer, B.; Tzourio-Mazoyer, N.; Joliot, M. Predicting Hemispheric Dominance for Language Production in Healthy Individuals Using Support Vector Machine. Hum. Brain Mapp. 2017, 38, 5871-5889. [CrossRef]

64. Bernal, B.; Ardila, A. Bilateral representation of language: A critical review and analysis of some unusual cases. J. Neurolinguist. 2014, 28, 63-80. [CrossRef]

65. Janecek, J.K.; Swanson, S.J.; Sabsevitz, D.S.; Hammeke, T.A.; Raghavan, M.; Rozman, M.E.; Binder, J.R. Language lateralization by fMRI and Wada testing in 229 patients with epilepsy: Rates and predictors of discordance. Epilepsia 2013, 54, 314-322. [CrossRef] [PubMed]

66. Moddel, G.; Lineweaver, T.; Schuele, S.U.; Reinholz, J.; Loddenkemper, T. Atypical language lateralization in epilepsy patients. Epilepsia 2009, 50, 1505-1516. [CrossRef]

67. Sun, T.; Walsh, C.A. Molecular approaches to brain asymmetry and handedness. Nat. Rev. Neurosci. 2006, 7, 655-662. [CrossRef] [PubMed]

68. Thomas, S.; Boutaud, L.; Reilly, M.L.; Benmerah, A. Cilia in hereditary cerebral anomalies. Biol. Cell 2019, 111, 217-231. [CrossRef]

69. Medina, L. Evolution and Embryological Development of Forebrain. In Encyclopedia of Neuroscience; Binder, M.D., Hirokawa, N., Windhorst, U., Eds.; Springer: Berlin/Heidelberg, Germany, 2009; pp. 1172-1192. [CrossRef] 
70. Sun, T.; Patoine, C.; Abu-Khalil, A.; Visvader, J.; Sum, E.; Cherry, T.J.; Orkin, S.H.; Geschwind, D.H.; Walsh, C.A. Early asymmetry of gene transcription in embryonic human left and right cerebral cortex. Science 2005, 308, 1794-1798. [CrossRef]

71. Fukuchi-Shimogori, T.; Grove, E.A. Neocortex patterning by the secreted signaling molecule FGF8. Science 2001, 294, 1071-1074. [CrossRef] [PubMed]

72. Puelles, L.; Martínez, S.; Martinez-de-la-Torre, M.; Rubenstein, J.L.R. Gene maps and related histogenic domains in the forebrain and midbrain. In The rat Nervous System; Paxinos, G., Ed.; Elsevier: Amsterdam, The Netherlands, 2004; pp. 3-25.

73. De Kovel, C.G.F.; Lisgo, S.N.; Fisher, S.E.; Francks, C. Subtle left-right asymmetry of gene expression profiles in embryonic and foetal human brains. Sci. Rep. 2018, 8. [CrossRef]

74. De Kovel, C.G.F.; Lisgo, S.; Karlebach, G.; Ju, J.; Cheng, G.; Fisher, S.E.; Francks, C. Left-Right Asymmetry of Maturation Rates in Human Embryonic Neural Development. Biol. Psychiatry 2017, 82, 204-212. [CrossRef]

75. Schmitz, J.; Lor, S.; Klose, R.; Gunturkun, O.; Ocklenburg, S. The Functional Genetics of Handedness and Language Lateralization: Insights from Gene Ontology, Pathway and Disease Association Analyses. Front. Psychol. 2017, 8, 1144. [CrossRef] [PubMed]

76. Abu-Rustum, R.S.; Ziade, M.F.; Abu-Rustum, S.E. Reference Values for the Right and Left Fetal Choroid Plexus at 11 to 13 Weeks An Early Sign of "Developmental" Laterality? J. Ultrasound Med. 2013, 32, 1623-1629. [CrossRef] [PubMed]

77. Vasung, L.; Rollins, C.K.; Yun, H.J.; Velasco-Annis, C.; Zhang, J.; Wagstyl, K.; Evans, A.; Warfield, S.K.; Feldman, H.A.; Grant, P.E.; et al. Quantitative In vivo MRI Assessment of Structural Asymmetries and Sexual Dimorphism of Transient Fetal Compartments in the Human Brain. Cereb. Cortex 2020, 30, 1752-1767. [CrossRef]

78. Kasprian, G.; Langs, G.; Brugger, P.C.; Bittner, M.; Weber, M.; Arantes, M.; Prayer, D. The Prenatal Origin of Hemispheric Asymmetry: An In Utero Neuroimaging Study. Cereb. Cortex 2011, 21, 1076-1083. [CrossRef]

79. Habas, P.A.; Scott, J.A.; Roosta, A.; Rajagopalan, V.; Kim, K.; Rousseau, F.; Barkovich, A.J.; Glenn, O.A.; Studholme, C. Early Folding Patterns and Asymmetries of the Normal Human Brain Detected from in Utero MRI. Cereb. Cortex 2012, $22,13-25$. [CrossRef]

80. Yun, H.J.; Vasung, L.; Tarui, T.; Rollins, C.K.; Ortinau, C.M.; Grant, P.E.; Im, K. Temporal Patterns of Emergence and Spatial Distribution of Sulcal Pits During Fetal Life. Cereb. Cortex 2020, 30, 4257-4268. [CrossRef]

81. Dubois, J.; Benders, M.; Lazeyras, F.; Borradori-Tolsa, C.; Leuchter, R.H.V.; Mangin, J.F.; Huppi, P.S. Structural asymmetries of perisylvian regions in the preterm newborn. Neuroimage 2010, 52, 32-42. [CrossRef]

82. Karlebach, G.; Francks, C. Lateralization of gene expression in human language cortex. Cortex 2015, 67, 30-36. [CrossRef]

83. Brandler, W.M.; Morris, A.P.; Evans, D.M.; Scerri, T.S.; Kemp, J.P.; Timpson, N.J.; St Pourcain, B.; Smith, G.D.; Ring, S.M.; Stein, J.; et al. Common Variants in Left/Right Asymmetry Genes and Pathways Are Associated with Relative Hand Skill. PLoS Genet. 2013, 9, e1003751. [CrossRef]

84. Brandler, W.M.; Paracchini, S. The genetic relationship between handedness and neurodevelopmental disorders. Trends Mol. Med. 2014, 20, 83-90. [CrossRef]

85. Moher, D.L.A.; Tetzlaff, J.; Altman, D.G.; The PRISMA Group. Preferred reporting items for systematic reviews and meta-analyses: The PRISMA statement. PLoS Med. 2009, 6, e1000097. [CrossRef]

86. Kienast, P.; Schwartz, E.; Diogo, M.C.; Gruber, G.M.; Brugger, P.C.; Kiss, H.; Ulm, B.; Bartha-Doering, L.; Seidl, R.; Weber, M.; et al. The Prenatal Origins of Human Brain Asymmetry: Lessons Learned from a Cohort of Fetuses with Body Lateralization Defects. Cereb. Cortex 2021. [CrossRef] [PubMed]

87. McManus, I.C. Reversed bodies, reversed brains, and (some) reversed behaviors: Of zebrafish and men. Dev. Cell 2005, 8, 796-797. [CrossRef]

88. Cockayne, E.A. The genetics of transposition of the viscera. Q. J. Med. New Ser. 1938, 27, 479-493.

89. Torgersen, J. Situs inversus, asymmetry and twinning. Am. J. Hum. Genet. 1950, 2, 361-370.

90. Papadatou-Pastou, M.; Ntolka, E.; Schmitz, J.; Martin, M.; Munafo, M.R.; Ocklenburg, S.; Paracchini, S. Human Handedness: A Meta-Analysis. Psychol. Bull. 2020, 146, 481-524. [CrossRef]

91. Everett, H.C. Situs Inversus Totalis-A Survey of Laterality and Some Observations on Frequency of Mental Disorder. Am. J. Psychiatry 1963, 119, 884. [CrossRef]

92. Matsumoto, T.; Kuriya, N.; Akagi, T.; Ohbu, K.; Toyoda, O.; Morita, J.; Ichikawa, K.; Matsuishi, T.; Hayashi, M.; Kato, H. Handedness and laterality of the viscera. Neurology 1997, 49, 1751. [CrossRef] [PubMed]

93. Mcmanus, I.C.; Martin, N.; Stubbings, G.F.; Chung, E.M.K.; Mitchison, H.M. Handedness and situs inversus in primary ciliary dyskinesia. Proc. R. Soc. B Biol. Sci. 2004, 271, 2579-2582. [CrossRef]

94. Woods, R.P. Brain Asymmetries in Situs-Inversus-A Case-Report and Review of the Literature. Arch. Neurol. 1986, 43, 1083-1084. [CrossRef]

95. Tanaka, S.; Kanzaki, R.; Yoshibayashi, M.; Kamiya, T.; Sugishita, M. Dichotic listening in patients with situs inversus: Brain asymmetry and situs asymmetry. Neuropsychologia 1999, 37, 869-874. [CrossRef]

96. Kennedy, D.N.; O'Craven, K.M.; Ticho, B.S.; Goldstein, A.M.; Makris, N.; Henson, J.W. Structural and functional brain asymmetries in human situs inversus totalis. Neurology 1999, 53, 1260-1265. [CrossRef]

97. Schuler, A.L.; Kasprian, G.; Schwartz, E.; Seidl, R.; Diogo, M.C.; Mitter, C.; Langs, G.; Prayer, D.; Bartha-Doering, L. Mens inversus in corpore inverso? Language lateralization in a boy with situs inversus totalis. Brain Lang 2017, 174, 9-15. [CrossRef]

98. Vingerhoets, G.; Li, X.; Hou, L.; Bogaert, S.; Verhelst, H.; Gerrits, R.; Siugzdaite, R.; Roberts, N. Brain structural and functional asymmetry in human situs inversus totalis. Brain Struct. Funct. 2018, 223, 1937-1952. [CrossRef] 
99. Cohen, L.; Geny, C.; Hermine, O.; Gray, F.; Degos, J.D. Crossed Aphasia with Visceral Situs-Inversus. Ann. Neurol. 1993, 33, 215-218. [CrossRef]

100. Ihara, A.; Hirata, M.; Fujimaki, N.; Goto, T.; Umekawa, Y.; Fujita, N.; Terazono, Y.; Matani, A.; Wei, Q.; Yoshimine, T.; et al. Neuroimaging study on brain asymmetries in situs inversus totalis. J. Neurol. Sci. 2010, 288, 72-78. [CrossRef]

101. Xiang, L.; Crow, T.; Roberts, N. Cerebral torque is human specific and unrelated to brain size. Brain Struct. Funct. 2019, 224, 1141-1150. [CrossRef]

102. Balzeau, A.; Gilissen, E.; Grimaud-Herve, D. Shared Pattern of Endocranial Shape Asymmetries among Great Apes, Anatomically Modern Humans, and Fossil Hominins. PLoS ONE 2012, 7. [CrossRef]

103. Tubbs, R.S.; Wellons, J.C.; Salter, G.; Blount, J.P.; Oakes, W.J. Intracranial anatomic asymmetry in situs inversus totalis. Anat. Embryol. 2003, 206, 199-202. [CrossRef]

104. Leroy, F.; Cai, Q.; Bogart, S.L.; Dubois, J.; Coulon, O.; Monzalvo, K.; Fischer, C.; Glasel, H.; Van der Haegen, L.; Benezita, A.; et al. New human-specific brain landmark: The depth asymmetry of superior temporal sulcus. Proc. Natl. Acad. Sci. USA 2015, 112, 1208-1213. [CrossRef] [PubMed]

105. Mannaert, L.; Verhelst, H.; Gerrits, R.; Bogaert, S.; Vingerhoets, G. White matter asymmetries in human situs inversus totalis. Brain Struct. Funct. 2019, 224, 2559-2565. [CrossRef] [PubMed] 